\title{
A systematic material-oriented design approach for lightweight components and the CFRP motor wheel case study
}

\author{
Davide Cocchi $^{1}$ (D) $\cdot$ Luca Raimondi $^{1} \cdot$ Tommaso Maria Brugo $^{1} \cdot$ Andrea Zucchelli $^{1}$
}

Received: 10 March 2020 / Accepted: 10 July 2020 / Published online: 26 July 2020

(C) The Author(s) 2020

\begin{abstract}
Lightweighting is a need in many industrial fields and, in particular, in transports, to reduce energy consumptions and to promote more environmentally friendly solutions. In this context, the use of composite materials has become ever more strategic, and a design approach that effectively combines shapes and materials is by now mandatory. In this work, the Systematic Design Approach has been extended to include potentialities and constraints related to materials and manufacturing at the early steps of the design flow. The proposed approach, named systematic material-oriented design approach, enables designers to identify and to select, in a systematic way, design solutions where shapes are tailored to materials and where benefits and criticalities related to the manufacturing processes are considered. In the paper, each design phase of the approach is described and applied to design the carbon fiber-reinforced polymer (CFRP) motor wheel of the Emilia 4 solar vehicle. Optimization steps of geometry and materials complete the approach. The design of the wheel is fully detailed as well as its manufacturing and bending tests under static and fatigue conditions. In particular, strain fields were measured with a 3D digital image correlation (DIC) system during static tests to validate the numerical model.
\end{abstract}

Keywords Carbon fiber composites · Systematic design approach · Motor wheel $\cdot$ Lightweight vehicles · FEA · Digital image correlation

$\begin{array}{ll}\text { Nomenclature } \\ \mathrm{m} & \text { Gross vehicle weight } \\ \mathrm{h}_{\mathrm{GC}} & \text { Centre of gravity height } \\ 1 & \text { Wheelbase } \\ \mathrm{a}_{1} & \text { Front semi-wheelbase } \\ \mathrm{a}_{2} & \text { Rear semi-wheelbase } \\ \mathrm{c}_{\mathrm{f}} & \text { Front track } \\ \mathrm{c}_{r} & \text { Rear track } \\ \mu_{\mathrm{t}} & \text { Transversal coefficient of } \\ & \text { friction (transversal grip) }\end{array}$

Electronic supplementary material The online version of this article (https://doi.org/10.1007/s00170-020-05756-2) contains supplementary material, which is available to authorized users.

Davide Cocchi davide.cocchi5@unibo.it

Andrea Zucchelli a.zucchelli@unibo.it

1 Dipartimento di Ingegneria Industriale, Alma Mater Studiorum Università di Bologna, viale del Risorgimento 2, 40136 Bologna, Italy $\mu_{1} \quad$ Longitudinal coefficient of friction (longitudinal grip)

g Acceleration of gravity

$\mathrm{a}_{\mathrm{x}} \quad$ Longitudinal acceleration

$\mathrm{a}_{\mathrm{x}, \max }$ Maximum longitudinal acceleration

$\mathrm{a}_{\mathrm{y}} \quad$ Transversal acceleration

$\mathrm{a}_{\mathrm{y}, \max } \quad$ Maximum transversal acceleration

$\Delta z_{\mathrm{f}} \quad$ Longitudinal load transfer during braking

$\Delta \mathrm{y}_{\mathrm{f}} \quad$ Front axle transversal load transfer in corner

$\Delta y_{\mathrm{r}} \quad$ Rear axle transversal load transfer in corner

$\mathrm{F}_{\mathrm{z}} \quad$ Vertical force on the wheel

$\mathrm{F}_{\mathrm{z} \text {,max }}$ Maximum vertical force on the wheel

$\mathrm{p}_{0} \quad$ Tire inflating pressure

$\mathrm{p}_{0, \max }$ Maximum tire inflating pressure

$r \quad$ Radius of the tire

$r_{f} \quad$ Radius of the rim

$\mathrm{T}_{\mathrm{f}} \quad$ Maximum load at the interface tire/rim flange due to pressure

$\mathrm{M}_{\mathrm{b}} \quad$ Bending moment

$\mathrm{M}_{\mathrm{b} \text {,max }}$ Maximum bending moment

$\mathrm{M}_{\mathrm{t}} \quad$ Torque moment

$\mathrm{F}_{\mathrm{p}} \quad$ Rolling load 
d Inset of the wheel

$\mathrm{S}_{\mathrm{b}} \quad$ Safety factor bending moment

$\mathrm{S}_{\mathrm{r}} \quad$ Safety factor rolling

$\mathrm{S}_{\mathrm{t}} \quad$ Safety factor torque

$\mathrm{E}_{1} \quad 0^{\circ}$ tensile modulus

$\mathrm{E}_{2} \quad 90^{\circ}$ tensile modulus

$\mathrm{G}_{12} \quad$ In-plane shear modulus (IPSM)

$v_{12} \quad$ Major Poisson's ratio

$\sigma_{\mathrm{t} 1} \quad 0^{\circ}$ tensile strength

$\sigma_{\mathrm{t} 2} \quad 90^{\circ}$ tensile strength

$\sigma_{\mathrm{c} 1} \quad 0^{\circ}$ compressive strength

$\sigma_{\mathrm{c} 2} \quad 90^{\circ}$ compressive strength

$\tau_{12} \quad$ In-plane shear strength (IPSS)

ILSS Interlaminar shear strength

IRF Inverse reserve factor [ultimate load]/ [ultimate strength]

\section{Introduction}

The design of lightweight components is a growing need in many industrial fields and, in particular, in transport applications that require low masses to contain energy consumption and to have a lower environmental impact $[1,2]$. The transport sector has begun a process of lightening that started in the contest of heavy-duty vehicles for passenger and goods, and today has a new frontier in the design of electric and hybrid light-duty vehicles for sustainable mobility. In this context, the use of composite materials, and in particular of fiberreinforced polymer (FRP), has become necessary [3], and a design methodology that effectively combines shapes and materials is mandatory.

In this work, we propose a new design approach that allows combining shapes and materials, and in particular composite, from the very first steps of its paradigm, and we present the application of this approach to the design, manufacture, and testing of the composite motor wheel for the Emilia 4 solar vehicle.

Several design methodologies for the development of composite components have been proposed in the literature. A comprehensive review of Concurrent Engineering design approaches for composite components is reported by Sapuan [4]. Other design methodologies for composite parts, like the one suggested by Monroy Aceves [5], were developed based on the material selection process proposed by Ashby and Johnson [6]. These methodologies represent a step forward in the integration of composite material in the component design process even if their application is not trivial, and no examples of their concrete use to design components with complex geometries and functionalities were found. Moreover, such methodologies do not enable designers to explore solutions that can derive from the crosscontaminations of different material classes.
The design approach here proposed is inspired by the engineering systematic design approach introduced by Pahl and Beitz [7]. The systematic design approach guides the designers to develop an extensive and credible range of conceptual solutions and to select, among them, the one which is the most compliant to the application requirements and constraints. This approach was initially established to design mechanical systems and components which are expected to be made by conventional materials and to be manufactured by traditional technologies. The extension of this approach to structural, and even esthetic, components to be realized by composite is not trivial because, for example, in the case of composite laminates, the stacking of plies generates a complex structure that can undergo several types of defects that could be introduced during manufacturing, tooling and finishing processes [8-14]. Furthermore, the connection of composite components to other parts requires the adoption of solutions that are much different with respect to ones adopted for components made by conventional material [15-21]. Finally, mechanical performances of composite parts can be deteriorated by a multitude and concomitant failure modes which are completely different with respect to what is experienced in the case of conventional materials, and this fact has to be accounted during the design process [22-25]. By the authors' knowledge, just a few examples of the extension of the systematic design approach to include composite materials, and the related manufacturing technologies, have been proposed in literature. For instance, Kaspar [26] proposes a systematic FRP design methodology within a lightweight and material-oriented development process, leading to a topologyoptimized and tailor-made material and process-specific system design. However, this approach is somewhat intricate and restrictive, leaving little degrees of freedom to designers to explore new functionalities and novel material combinations. Mastura and others [27], instead, propose a product-oriented hybrid approach that combines quality function deployment, theory of inventive problem solving, and blue ocean strategy for the development of a natural fiber-reinforced composite component. However, their work only concerns the conceptual design phase, and nothing is reported about the experimental tests to validate their approach.

In this paper, the systematic design approach has been modified by including materials and related manufacturing processes in the main design flow. Such an approach gives designers the freedom in the choice of materials, including composites, and enables the systematic evaluation of their impact on design solutions. In the paper, each phase of the approach is described in detail including an extensive collection of examples of composite materials and their applications which are useful for the development of conceptual design solutions. Moreover, the proposed approach includes optimization steps of geometry and materials which are developed consequentially to have greater control on intermediate results 
and to reduce the computing time. In the paper, we present the application of the proposed systematic material-oriented design approach to the motor wheel project of solar vehicle Emilia 4.

\section{The design approach}

The proposed approach is based on a consolidated design for function procedure, originally proposed by Pahl and Beitz [7]. As summarized in Fig. 1, the systematic design approach consists of 4 macro phases: (i) the task clarification phase, (ii) the conceptual design phase, (iii) the structural design and calculation phase followed by (iv) manufacturing and experimental validation. In the traditional approach, the selection of materials and manufacturing processes is performed only at the structural design phase and this limits the classes of materials that can be directly adopted. To include also composite materials and the related manufacturing processes in the design flow, materials and processes have to be introduced at the early stage. In particular, thanks to the task clarification phase, it is possible to identify the suitable classes of materials, eventually using Ashby charts with CES selection engine (Granta Design Ltd., 2015) [28-30], and the related manufacturing processes (Fig. 1b). Material classes and processes influence the development of the conceptual design phase which is used to identify the design solution most compliant to the project tasks and the most suitable materials among the ones available in the previously selected classes. During the structural design phase, optimization procedures are applied to find the optimal solution in terms of geometry and material (e.g., in the case of composite laminate, the optimal laminate type and staking sequence).

The proposed approach is graphically represented in detail in Fig. 2. The four main phases are presented in blocks where for each of them, the most relevant steps are reported. About the material, in Fig. 2, there are two boxes highlighted with dotted lines: one is referred to the material class identification and process selection, while the second one represents the selection of the material followed by its optimization. To simplify the graphical representations of links between blocks related to the materials and the others, two symbols and arrows of different colors have been sketched: the symbol "“*” with red arrow represents the link of material class identification and process selection to other activities in the conceptual design phase, while the symbol " $\otimes$ " with blue arrow represents the link of material selection to other activities in the structural design, manufacturing, and testing phases.

In the following sections, both design approach phases and their application to the case of the motor wheel are explained. In particular, the task clarification phase and the identification of material classes are described in Section 3, while the conceptual design phase and considerations about materials and processes are reported in Section 4. In Section 5, the structural design is exposed. Finally, in Section 6, the manufacturing is described and in Section 7, the experimental test procedure and results are presented and discussed.

\section{Task clarification and identification of material classes}

The clarification of the project task aims to define the main function and the related requirements and constraints, taking into account what is already known from the state of the art (Fig. 2). This phase is organized into four main steps, described in the following paragraphs. The material class identification and the related manufacturing processes are discussed immediately after the task clarification phase.

\subsection{Main function}

The main function of a motor wheel is to interface the vehicle to the road and to move it. (a) Traditional Systematic DeSign APPROACH

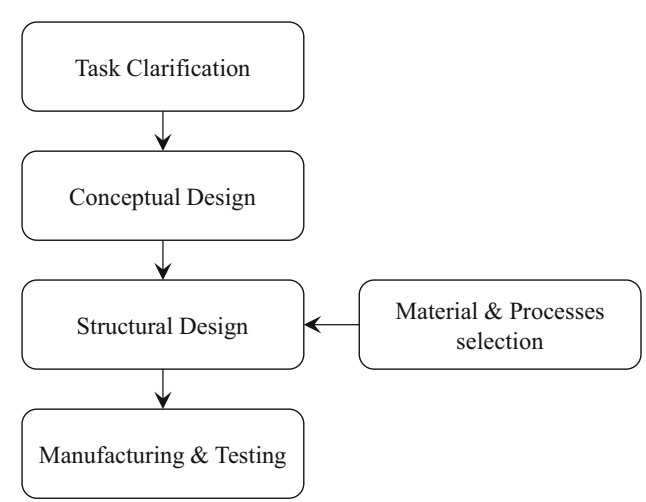

(b) SYSTEMATIC MATERIAL-ORIENTED DESIGN APPROACH

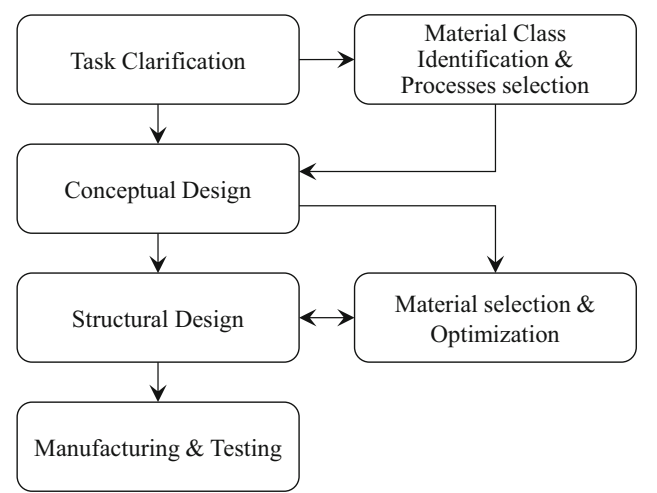

Fig. 1 Comparison between the a traditional systematic design approach and $\mathbf{b}$ the material-oriented version 


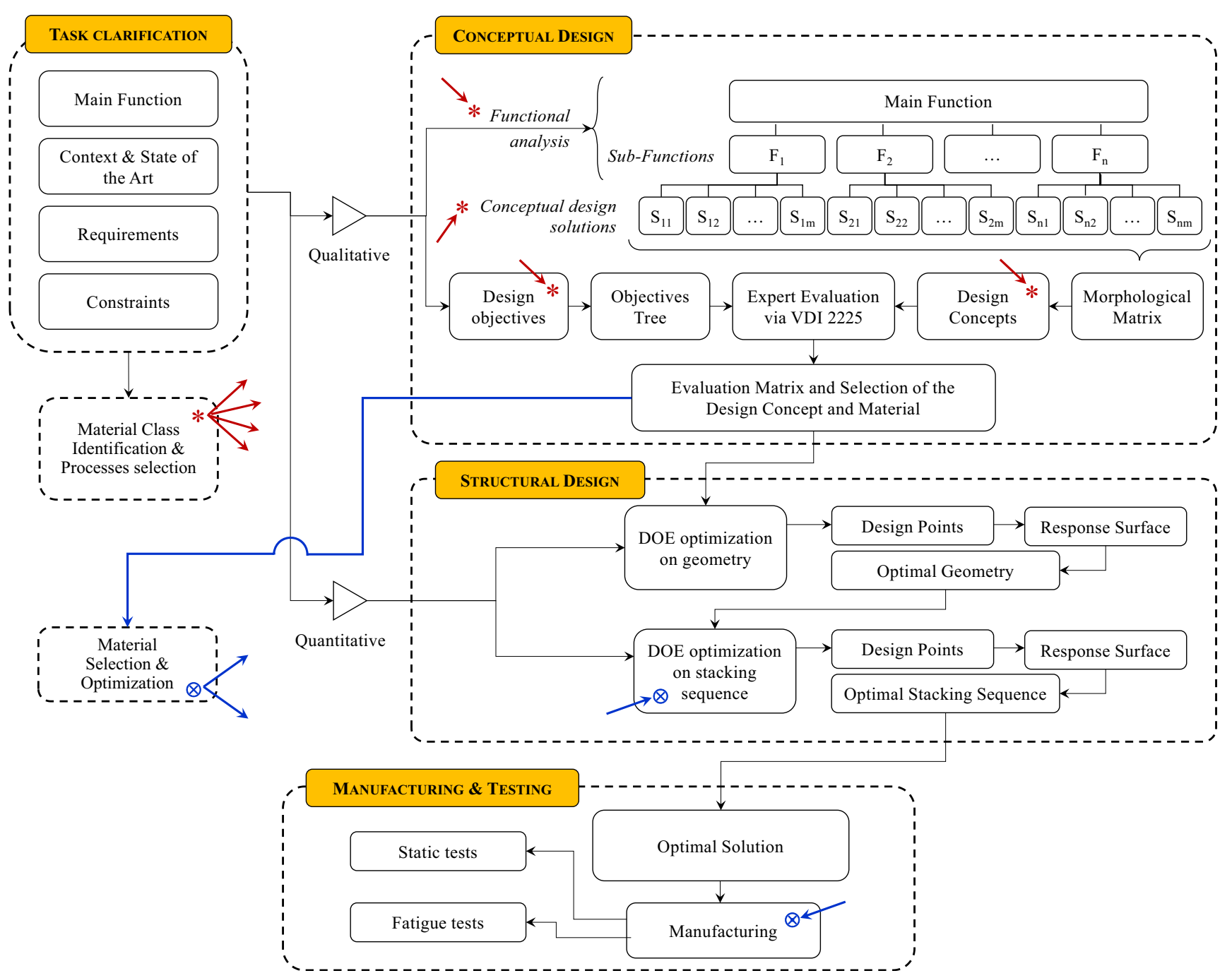

Fig. 2 Design approach flow

\subsection{Context and state of the art}

In the case of a motor wheel for a solar vehicle, some specific issues must be considered. The development of a solar vehicle is a challenge that has been studied for years because to get out the most of the power generated by solar cells, a strong effort must be paid in reducing the vehicle weight and in minimizing aerodynamical, electrical, and mechanical losses [31-33]. In particular, to optimize power consumption, the design of highefficiency powertrain is a crucial aspect. Since 1993, directdrive in-wheel motor ("motor wheel") has been adopted in several solar vehicles to reduce transmission losses and to increase efficiency, as reported by Lovatt and others [34]. In particular, they found that the electrical efficiency of an inwheel brushless machine increases with its weight, and therefore, to compensate for the unsprung mass increment, it would be necessary to lighten the wheel. Such a goal can be achieved by employing FRP materials for their high specific stiffness and strength. The idea of using FRP to manufacture wheels is not new, and it was initially explored to realize lightweight and high-performance wheels for conventional cars. Design and production of FRP wheels for passenger cars date back to the early 1970s, but until today, it was limited to small series or prototypes. According to Tomasini and others [35], limiting issues to a widespread diffusion of FRP wheels for conventional cars are thermal stability of the material and lack of standards and directives for a damage-tolerant design. However, compared to an internal combustion engine vehicle, where most of the heat in the rim is produced by brakes, in the case of an electric vehicle, the high-temperature problem is drastically reduced thanks to regenerative braking. The design of the first in-wheel electric motor for solar car application was reported in 1998 by Lovatt and others [34]. However, their work was focused on the design of the electric motor 
and not on the mechanical parts. The first proof of concept on the development of an integrated FRP motor wheel, to achieve the optimum of lightweight potential, was reported by Schweizer and others in 2012 [36]. However, their study lacks detailed information regarding the design phase and the optimization of the FRP stacking sequence. Moreover, production and tests are not reported. In the present paper, lacks in the literature related to the design and realization of motor wheels for solar vehicles are answered.

\subsection{Requirements}

Following the state of the art, a strategic requirement is the minimum weight of the motor wheel in order to reach the best performances in both rolling inertia and vehicle dynamics. Additional general requirements for the wheel of Emilia 4 are the following: (i) to support the solar car in a fully loaded configuration (4 passengers); (ii) to pass the qualification tests; (iii) to last, at least, a single race; and (iv) to guarantee the safety of occupants.

\subsection{Constraints}

An essential constraint is the compactness of the motor wheel, necessary to fit it into the limited chassis space of the solar vehicle Emilia 4. Geometrical constraints are represented in Fig. 3, in which the overall dimensions of the wheel and the

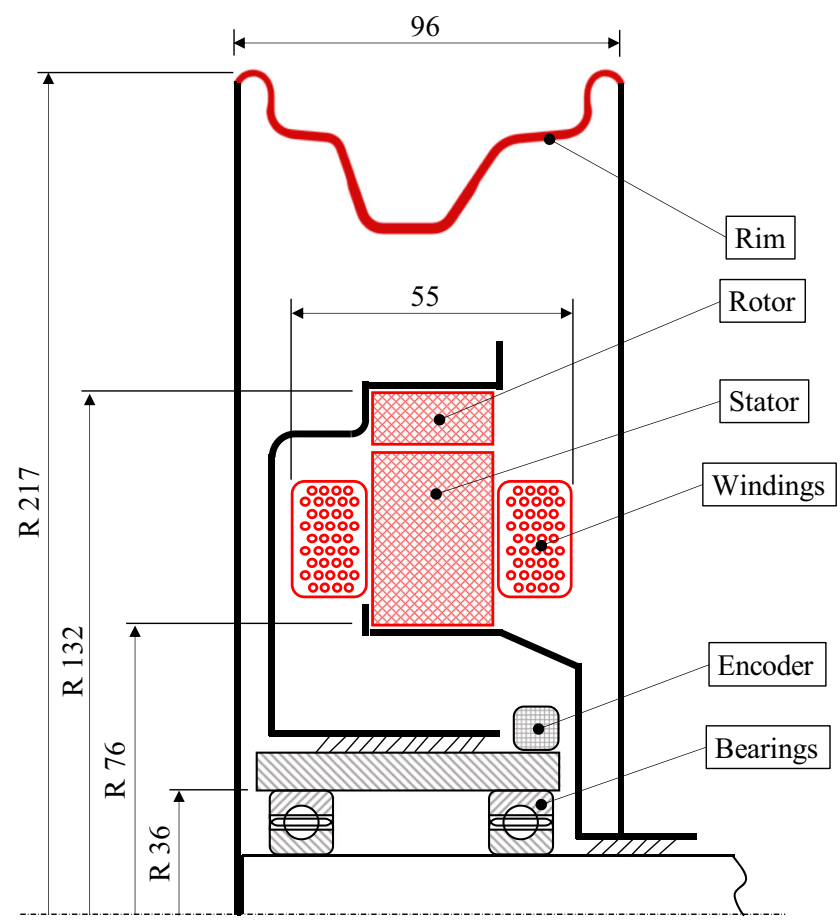

Fig. 3 Overall dimensions (expressed in $\mathrm{mm}$ ) and geometrical constraints in red electric motor are shown. Other important constraints, highlighted in red in Fig. 3, are (i) the rim profile, given by the tires supplier of the $16^{\prime \prime}$ pneumatic, developed explicitly for solar races and (ii) the type and size of the electric motors, already developed and optimized by the electrical experts of the Onda Solare team [37].

Regarding the material class identification, using the Ashby charts [28], it is possible to identify the proper class of material which is most compliant with the requirements related to minimum weight, to safety and to compactness. To represent these requirements in Ashby charts, specific strength and specific stiffness were adopted as selection parameters. Thanks to both plots of the Young modulus and the yield strength versus density, it is possible to observe that carbon fiber-reinforced polymer (CFRP) material class is the most compliant with the requirements and that it gives to the designer the higher leverages with respect to stiffness/mass and strength/mass ratios. Among the manufacturing process available to produce CFRP components, the one here adopted is the hand-layup followed by the autoclave curing process using the vacuum bag technique. This choice was made due to the limited number of prototypes that have been foreseen for the production (10 wheels).

\section{Conceptual design and considerations about materials and processes}

The development of the conceptual design, after the clarification of the project tasks and the identification of the material class and manufacturing process, consists of the following steps (Fig. 2):

1. The functional analysis, which aims to identify the essential sub-functions $\left(\mathrm{F}_{1}, \mathrm{~F}_{2}, \ldots, \mathrm{F}_{\mathrm{n}}\right)$ which, when combined, allow the component to fulfill the main function

2. The identification of several conceptual design solutions $\left(\mathrm{S}_{\mathrm{i} 1}, \mathrm{~S}_{\mathrm{i} 2}, \ldots, \mathrm{S}_{\mathrm{im}}\right)$ for each sub-function defined in step 1), organized in the morphological matrix

3. The combinations of the conceptual design solutions, identified in step 2, to obtain several design concepts

4. The definition of the design objectives, based on requirements and constraints identified in the task clarification phase

5. The construction of the objectives tree, where the design objectives are listed and related to relevance weights, necessary for the evaluation of the design concepts

6. The evaluation of each design concept using the relevance weight defined in the objective tree to obtain the optimal design concept.

During the functional analysis, the component is analyzed to identify primarily the essential elements that compose it 
and, therefore, the functions that each of them performs. The list of functions must be essential and without logical repetition. In the case of the wheel, 6 main sub-functions have been identified: (1) the wheel centering, (2) the wheel fixing, (3) the torque transmission, (4) the connection of the wheel hub to the rim, (5) the connection of the wheel disc to the rim, and, finally, (6) the structural health monitoring. It is worth mentioning that the last function is peculiar to applications based on the use of composite materials [38, 39]. Composites, and in particular composite laminates, are susceptible to several failure modes that are, in most of the cases, not detectable by visible inspection, and they rapidly degenerate to a catastrophic failure without clear evidence in advance [24]. Therefore, especially when safety is an issue, it is strategic to provide a function for monitoring structural integrity.

The conceptual design solutions for each sub-function are identified by analyzing all possible geometries, physical principles, their combinations, and using all potentialities that composite materials have in terms of strength/weight and stiffness/weight ratios. Additional potentialities of composite laminates which can be used during the identification of conceptual design solutions are related to local and gradual tuning of stiffness's component, without any significant impact on the final geometry [40, 41]. Moreover, the use of functional composites enables the identification of smart conceptual solutions without any increment in weight and geometrical complexity. Self-sensing and self-powered materials are examples of smart composite that enable the development of smart conceptual design solutions [42, 43]. Nevertheless, all limits related to composites such as plies assembly constraints (e.g., minimum bending radii), special care in tooling and finishing (e.g., drilling, milling, coating), and their in-service use (sensitivity to shocks and impacts) have to be accounted [44]. In the case of the wheel under consideration, in Fig. 4, the identified conceptual design solutions for the six sub-functions are reported in the morphological matrix. In particular, for the wheel centering sub-function, two solutions have been identified: using (1A) straight pins and (1B) a cylindrical/conical coupling surface. Solution (1A), because of the composite wheel, requires the use of metal inserts to be integrated during the lamination phase $[45,46]$, while solution (1B) requires special care on geometrical tolerances to realize the cylindrical or conical coupling surfaces. For this sub-function, solutions based on physical phenomena, such as forces deriving from magnetic fields, are not considered because they would have caused an increase in the final weight of the wheel, and they could interfere with the control of the electrical motor. For the wheel fixing sub-function, two conceptual design solutions have been founded: one based on the use of $(2 \mathrm{~A})$ several bolted connections and one that provides for the use of (2B) a single central ring nut. For both solutions, a specific design must be adopted to reduce the contact pressure between the surface of the laminated composite material and the heads of the screws or ring nut $[47,48]$. Three solutions have been identified for the torque transmission sub-function: the first one involves the use of (3A) straight pins, the second one is based on (3B) bolted connections, and the third one requires the use of (3C) shaped connections. The realization of solutions ( $3 \mathrm{~A})$ and $(3 \mathrm{~B})$ in a composite wheel requires to integrate inserts during the lamination phase, while solution (3C) requires care on geometrical tolerances and surface finishing of the surfaces transmitting torque.

Three solutions have been identified for the sub-function wheel hub to rim connection (wheel disk type): (4A) implementing spokes, (4B) using a lens, and (4C) adopting a hybrid solution that combines spokes and lens. All three solutions can be realized through the use of composite laminates, also having the possibility of obtaining tunable stiffness by modifying the local lamination sequence. Nevertheless, solution (4A) requires shaping prepreg plies following spokes geometry, and special care, during the design and the manufacturing, has to be used to prevent the risk of edge delamination as well as fiber misalignment [49]. Solution (4B) requires pre-cutting several circular plies that have to be carefully laminated to obtain quasi-isotropic effects. Solution (4C) requires the adoption of all the measures of the previous solutions. Besides, special attention must be paid to the resin pockets that may occur in overlapping areas between spokes and lens [50].

In the case of the rim-wheel disc connection sub-function, three solutions have been identified: one based on $(5 \mathrm{~A})$ bolted connections, one (5B) using rivets, and another one based on (5C) co-curing or adhesive bonding. The first solution (5A) requires the use of bushes that might be integrated into the lamination of both the rim flange and the wheel disc, and it requires the adoption of specific manufacturing solutions to guarantee the matching of holes. The second $(5 \mathrm{~B})$ requires drilling composite parts. The third one $(5 \mathrm{C})$ requires, in the case of co-curing, the proper calculation and manufacturing of the joining surface to enable the best stress distribution and the correct assembly of parts. Also, in the case of adhesive joining, attention has to be paid on deformation after curing and on surfaces finishing [51].

Finally, for the structural health monitoring sub-function, two solutions have been proposed that allow continuous monitoring and one that provides for scheduled inspections [52]. For continuous monitoring, the solutions considered are the following: (6A) the acoustic emission technique, which requires the use of piezoelectric sensors bonded on the wheel surface [53, 54], and (6B) the use of self-sensing materials to be integrated into the composite laminate [55-57]. The third solution $(6 \mathrm{C})$ is based on ultrasound inspection and can only be carried out when the vehicle is stationary [58].

The next step of the design process consists of the assembling of conceptual design solutions to obtain design concepts. Based on the conceptual design solutions in the 


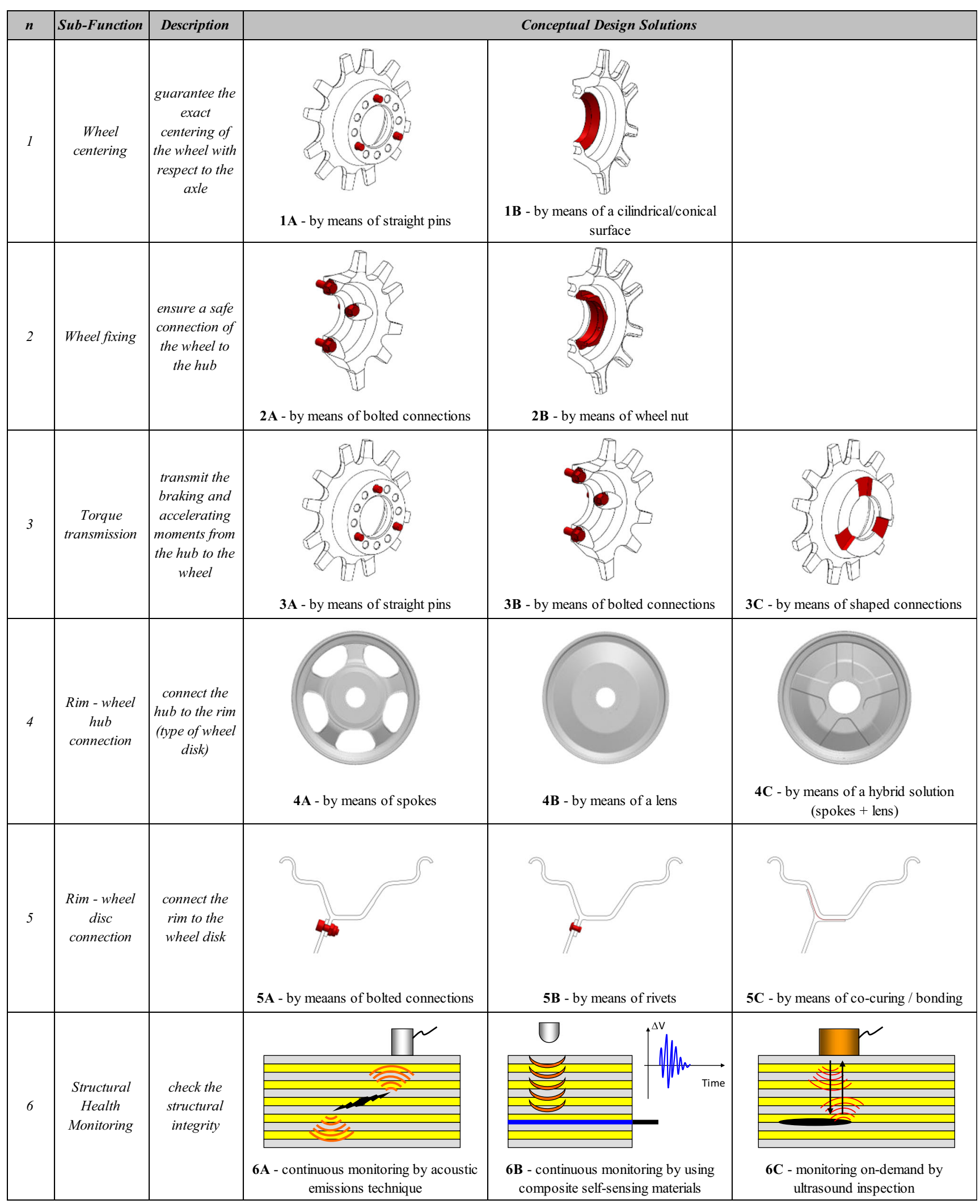

Fig. 4 Morphological matrix

morphological matrix in Fig. 4, three design concepts have been proposed and graphically represented in Fig. 5. The design concepts A and B provide the wheel centering and the torque transmission using straight pins insisting on 

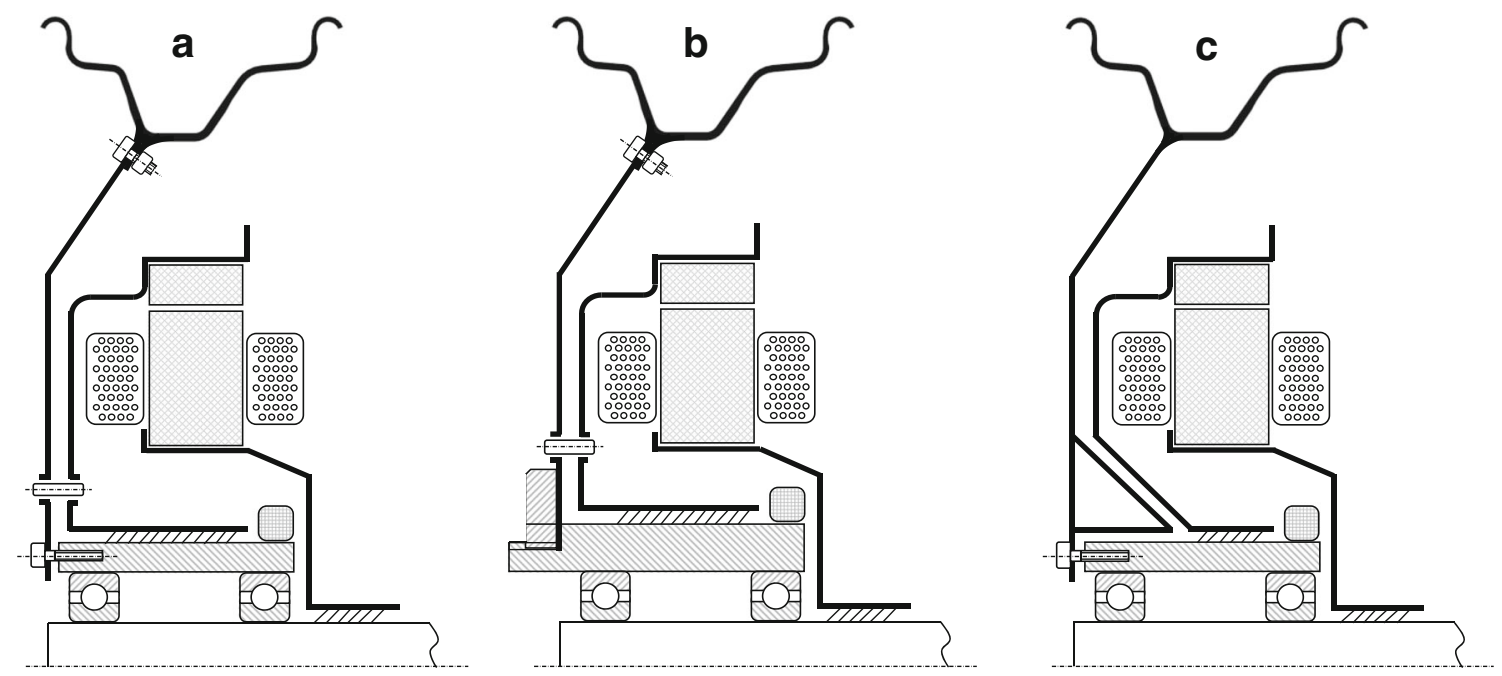

Fig. 5 Three candidate design concepts resulting from the conceptual design

cylindrical bushes (solutions (1A) and (3A) in the morphological matrix, Fig. 4). While fixing sub-function is performed through bolted connections for design concept A (solution (2A), Fig. 4) and through a wheel nut for design concept B (solution (2B), Fig. 4). Design concept $C$ provides the wheel centering and the transmission of the torque moment using interlocking protrusions, hereinafter "noses" (conceptual design solutions (1B) for centering and (3C) for torque transmission, Fig. 4) directly obtained during the lamination process. Moreover, the fixing of the wheel is granted by means of threaded connections (solution (2A), Fig. 4). For the design concepts $\mathrm{A}$ and $\mathrm{B}$, the connection between the rim and the wheel disk is granted by bolted connections (solution (5A), Fig. 4), while design concept $\mathrm{C}$ provides an undetachable assembly (solution (5C), Fig. 4). All these design concepts are conceptualized to reduce external load transmission from the wheel to the rotor, which could be hazardous for the electric motor.

Despite the goodness of the described design concepts, each of them presents minor specific limitations. Indeed, design concepts A and B require a much higher number of components than design concept $\mathrm{C}$ for torque transmission and wheel centering. As previously mentioned, to install straight pins on FRP components, it is necessary to integrate cylindrical bushes during the manufacturing process of the wheel. This task can be approached either by co-curing the bushes with the laminate directly in the mold or by fitting them into the cured part after drilling. Both design concepts provide external components connected directly to the laminate, so reducing the bearing strength of the overall part [23]. On the other side, design concept $\mathrm{C}$ overcomes this problem by integrating shaped connection directly in the mold and so in the final component. Moreover, with this design, it is possible to reduce the contact pressure thanks to an increased contact area on both sides of the noses. Interestingly, design concept B provides an easy and fast way to lock the wheel to the hub thanks to the single-wheel nut. However, in this case, more space is required for this kind of connection.

Regarding the wheel disk-rim connection, all three design concepts provide the connection in the central part of the rim, which is supposed to be the stiffer one. Design concepts A and $\mathrm{B}$, based on a modular bolted connection, allow to remove and to change the components easily in case of damage. However, these design concepts are potentially heavier than the permanent connection proposed with design concept $\mathrm{C}$, due to the presence of the bolts and a reasonably thick flange on the rim. Concerning the sub-function (4) of the morphological matrix (wheel disc type), solution (4C) proposed in Fig. 4 appears to be an efficient compromise between structural and aerodynamic performances for all three candidate design concepts. Since the motor wheels operate inside a closed compartment within the body of the vehicle, where no significant air inlets are permitted, the choice was to use a hybrid lenticular wheel disc with reinforcing spokes, in order to minimize the aerodynamic turbulence induced by the rotation of the wheel.

For the structural integrity monitoring sub-function, ultrasound control was chosen for all three design concepts. Such a solution has been adopted because of the racing purposes of the wheel, where weight is paramount. Real-time monitoring based on acoustic emission is a mass-expensive solution because it requires acquisition instrumentations directly on board of the vehicle. Self-sensing materials do not require heavy transducers, but they need electronic instrumentation and Wi-Fi transponders, impacting the final weight.

The next step of the conceptual design requires the selection of the best design concept via a systematic evaluation approach. Such an approach requires the identification of specific design criteria. Such criteria can be derived from the 
drawing up of a set of design objectives and assigning them a relative relevance value. The set of design objectives came from general constraints (e.g., limitations in dimensions) and from the list of requirements, which can be technical (e.g., mechanical and thermal performances, chemical behavior) and economical [7]. Examples of design objectives should be as follows: "technical quality", "ergonomics and comfort", "operational quality", and "cost". The importance of each design objective comes from the requirements and the constraints resulting from the task clarification phase. Individual design objectives are usually arranged in a hierarchical order generating an "objectives tree" structure, where several subobjectives can be defined for each design objective. In this way, the sub-objectives are arranged vertically into levels of decreasing complexity, and horizontally into the objective areas, such as technical, economic, etc. As a general rule, sub-objectives have to be independent, and for this reason, each of them may be connected with only one objective of the highest level. This hierarchical order helps the designer to determine whether or not all decision-relevant sub-objectives have been covered. Associated with the objective named technical quality, it is possible to link sub-objectives like "high strength", "high stiffness", "low weight", "high damping", "high safety", "high reliability", and "high durability". Possible sub-objectives linked to ergonomics and comfort can be the following: "easy to use", "suitable for long-time continuous use", and "suitable for intuitive use". Possible subobjectives for operational quality are the following: "easy to manufacture", "easy to install", "easy to remove", "easy to recycle", "easy to disassemble", and "easy to maintain in service". Finally, examples of sub-objectives linked to the cost can be the following: "low manufacturing cost", "low cost of maintenance", "low cost of recycling", and "low cost for second use".

In the case under study, it was decided to use two design objectives (Fig. 6): one related to technical quality $\left(\mathrm{O}_{11}\right)$ and the other one related to operational quality $\left(\mathrm{O}_{12}\right)$. Ergonomics and comfort and cost design objectives are not considered here because they are not entirely coherent with the racing purpose of the motor wheel. Moreover, the technical design objective was given greater importance $(60 \%)$ compared to the operational design objective $(40 \%)$ because it was decided to prioritize performance than operational aspects. The sub-objectives for technical quality were selected to satisfy the requirements relating to performance and safety: low weight $\left(\mathrm{O}_{111}\right)$, high safety $\left(\mathrm{O}_{112}\right)$, and high reliability $\left(\mathrm{O}_{113}\right)$. The low weight and the high safety objectives have the same relevance in order to induce the evaluators to consider the reduction of the mass significant without losing the attention on safety. At the same time, the sub-objective high reliability has been introduced to ensure that the wheel has to complete at least a single race. Sub-objectives related to operational quality have been identified to evaluate the design solutions considering the manufacturing ease and the component easy usage during the race: "simple manufacturing" $\left(\mathrm{O}_{121}\right)$, "simple maintenance" $\left(\mathrm{O}_{122}\right)$, and "easy installation" $\left(\mathrm{O}_{123}\right)$. The manufacturing sub-objective is the one that has a higher weight than others because of the lamination process of the FRP laminate. The lamination of different plies of reinforced fiber prepreg is a complex process by its nature. Consequently, to simplify the

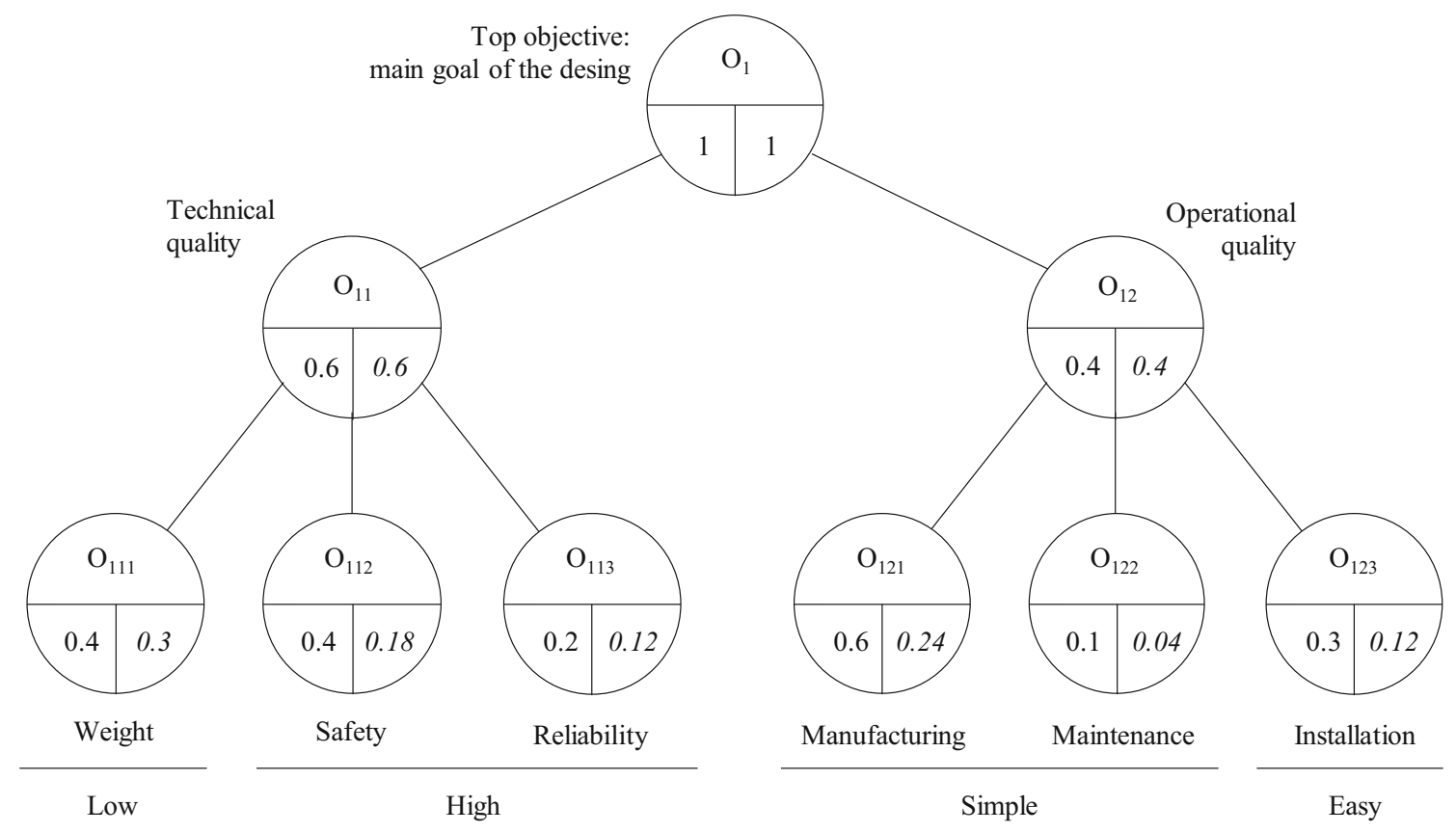

Fig. 6 The objectives tree with the design objectives and their relevance weights 
manual overlapping and compression phases of the prepreg layers, when possible, it is better to choose simple geometries, with a smooth and a reduced number of shape variations, as well as simple manufacturing solutions (e.g., reduced number of tools and assemblies). The sub-objective "installation" has a higher weight than "maintenance" one because of the purpose for which the wheel is designed. In fact, during the race, any substitution of the wheel must be carried out as quickly as possible. On the contrary, if possible, a damaged wheel should be maintained, but this event is less relevant in percentage weight than the other sub-objectives related to operational quality.

The last step of the conceptual design process concerns the evaluation of the design concepts to identify the one that best meets the requirements contained in the objective tree. Expert judgment is used to apply the requirements listed in the objective tree to the design concepts. The experts have to analyze the design concepts, and they have to assign a score to each sub-objective. In the case studied here, it was decided to use the scale of scores suggested in VDI 2225 [59]. This standard provides that when a specific sub-objective can be achieved in a "very good" manner, experts give a score of 4 , while the score is 0 if the analyzed design concept is "unsatisfactory." Five experts in the field of composite materials, outside the research group, were interviewed for the motor wheel project and related tasks. Their assessments were collected using the evaluation form reported in the Supplementary Information (SI1). Note that in the form, each expert was asked to express an evaluation of each design concept following the list of subobjectives without weights. This choice was made in order not to influence the experts' judgments.

In Table 1, the results of the evaluation process are summarized. In particular, the average (Avg) and the standard deviation (SD) of the score given by evaluators are reported. It is worth mentioning that the standard deviation is interesting information about the accordance within the evaluators' panel about the satisfaction of the objective for each design concept.

The multiplication of each Avg score with the corresponding absolute weight is the weighted score (WS) of each objective. The sum of the weighted scores is used to prepare the hit of the design concept. The highest total score of 3.07 was achieved by design concept $\mathrm{C}$, which provides the following characteristics: interlocking noses for torque transmission, a cylindrical surface for wheel centering, bolted connection for wheel fixing, co-curing for wheel disk-rim connection, and a hybrid wheel disk. It is interesting to note that for all design concept solutions, the SD of the objectives scores is very limited which represent a good accordance within the evaluator panel. The optimal design concept $\mathrm{C}$, identified during the conceptual design phase, is then optimized during the structural design phase, described in Section 5. It must be noticed that during the application of the proposed approach, depending on the production process, a high number of iterations between designers and producers could be required to verify the manufacturability. Moreover, the optimization of processing parameters, depending on the material, needs to be tuned for each case study.

\section{Structural design}

Structural design phase is performed on the result of the conceptual design phase. Due to the complexity of the design of FRP structures, the structural design phase has been subdivided, for computation time convenience, in two steps (Fig. 2): the optimization of geometrical parameters and the optimization of the stacking sequence.

In this phase, indeed requirements and constraints are quantitatively considered. Therefore, the external loads applied on the wheel are calculated (Paragraph 5.1) and a preliminary stacking sequence is proposed (Paragraph 5.2). The design goal is to minimize the mass within an acceptable stiffness and an allowable safety margin, by means of finite element analysis (FEA) and design of experiments (DOE) method over a numerical model (Paragraph 5.3). Geometrical optimization and laminate stacking sequence optimization are discussed in Paragraph 5.4 and Paragraph 5.5 respectively.

Table 1 Computation of the scores for the three candidate design concepts, according to VDI 2225 standard

\begin{tabular}{|c|c|c|c|c|c|c|c|c|c|c|c|c|c|}
\hline \multicolumn{5}{|c|}{ Design objectives } & \multicolumn{3}{|c|}{ Design concept A } & \multicolumn{3}{|c|}{ Design concept B } & \multicolumn{3}{|c|}{ Design concept $\mathrm{C}$} \\
\hline ID & Objective & Attribute (to be ...) & Relative weight & Absolute weight & Avg & SD & WS & Avg & SD & WS & Avg & $\mathrm{SD}$ & WS \\
\hline $\mathrm{O}_{111}$ & Weight & Low & 0.4 & 0.24 & 2.04 & 0.10 & 0.49 & 2.11 & 0.13 & 0.51 & 3.10 & 0.12 & 0.74 \\
\hline $\mathrm{O}_{112}$ & Safety & High & 0.4 & 0.24 & 3.36 & 0.30 & 0.81 & 2.20 & 0.24 & 0.53 & 3.37 & 0.27 & 0.81 \\
\hline $\mathrm{O}_{113}$ & Reliability & High & 0.2 & 0.12 & 3.08 & 0.34 & 0.37 & 1.10 & 0.17 & 0.13 & 3.04 & 0.15 & 0.36 \\
\hline $\mathrm{O}_{121}$ & Manufacturing & Simple & 0.6 & 0.24 & 1.91 & 0.27 & 0.46 & 2.10 & 0.25 & 0.50 & 2.97 & 0.30 & 0.71 \\
\hline $\mathrm{O}_{122}$ & Maintenance & Simple & 0.1 & 0.04 & 2.14 & 0.15 & 0.09 & 2.64 & 0.21 & 0.11 & 1.98 & 0.22 & 0.08 \\
\hline \multirow[t]{2}{*}{$\mathrm{O}_{123}$} & Installation & Easy & 0.3 & 0.12 & 2.93 & 0.23 & 0.35 & 3.51 & 0.21 & 0.42 & 2.98 & 0.21 & 0.36 \\
\hline & & & & & Total & & 2.56 & Total & & 2.20 & Total & & 3.07 \\
\hline
\end{tabular}



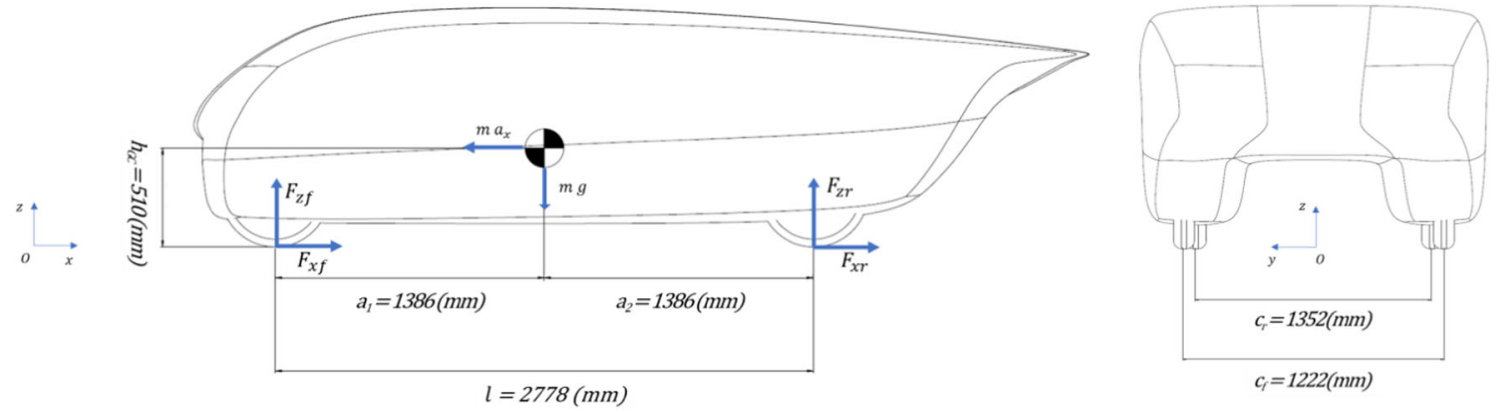

Fig. 7 Overall dimensions, forces, and positioning of the centre of gravity of the solar vehicle Emilia 4

\subsection{Load calculations}

Design loads on the wheel have been calculated by means of classical vehicle dynamics analysis. Overall dimensions, forces, and positioning of the center of gravity of the vehicle are represented in Fig. 7.

Assuming a gross vehicle weight rating $m$ of $660 \mathrm{~kg}$ with a symmetric distribution in the longitudinal $x$ and side $y$ axis, load transfer in braking can be calculated as $\Delta z_{f}=m h_{G C} a_{x} / l$, from equilibrium equations. Moreover, maximum value for $a_{x}$ can be obtained by knowing the longitudinal grip $\mu_{l}$ of the tire as $a_{x, \max }=\mu_{l} g$. Denoting by $c_{f}$ and $c_{r}$, respectively, the size of the front and rear track of the car, lateral load transfer for front and rear axle can be calculated as $\Delta y_{f}=m h_{C G} a_{y} / c_{f}$ and $\Delta y_{r}=$ $m h_{C G} a_{y} / c_{r}$. Similarly, maximum value for $a_{y}$ is obtained from the lateral grip of the tire $\mu_{t}$ as $a_{y, \max }=\mu_{t} g$. The values of the friction coefficients, experimentally validated by means of accelerometer tests on the previous prototype Emilia 3, which uses the same tires, are $\mu_{l}=0.9$ and $\mu_{t}=0.6$.

Maximum load transfer in braking is estimated to be $1073 \mathrm{~N}$ while lateral load transfer in cornering is expected to be $732 \mathrm{~N}$ for the front axle and $810 \mathrm{~N}$ for the rear axle. Maximum calculated components of the forces acting on the tire in both braking and cornering are reported in Table 2.

From the results, it is worth to mention that cornering is the most severe working condition, and, for this reason, it is considered in the next calculations. The combination of braking and cornering is neglected because this kind of competitions does not include tests in which the wheel is stressed with

Table 2 Force components acting on the tire during braking and cornering

\begin{tabular}{lll}
\hline Force component & Braking $(N)$ & Cornering $(N)$ \\
\hline Vertical $F_{z}$ & 2154 & 2428 \\
Lateral $F_{y}$ & 1293 & 1457 \\
Longitudinal $F_{x}$ & 1939 & 2186 \\
\hline
\end{tabular}

combined loads (e.g., Fig. 8 course, slalom course, braking test). According to the E/ECE/324 R124e Regulation, the maximum load capacity $F_{z, \max }$ is considered for the design of the wheel. Three loading conditions are therefore separately considered: (1) bending moment, (2) torque, and (3) rolling. The relevant formulas are

$M_{b, \max }=S_{b} F_{z, \max }\left(\mu_{t} r+d\right)$

$M_{t}=S_{t} F_{z, \max } r$

$F_{p}=S_{r} F_{z, \max }$

From the relationship (1), (2), and (3), assuming suggested safety factors values $\left(S_{b}=2, S_{r}=2.5, S_{t}=1\right)$, a bending moment $M_{b, \max }$ of $1027 \mathrm{Nm}$, a rolling testing force $F_{p}$ of $6071 \mathrm{~N}$, and a torque $M_{t}$ of $678 \mathrm{Nm}$ are obtained. Impact load case is neglected due to the racing application of this wheel. Moreover, in combination with the three loading conditions prescribed by the regulation, the effects of the inflation pressure are considered. The maximum load at the interface between the tire and the rim flange is calculated using the expression $T_{f}=\left(r^{2}-r_{f}^{2}\right) \frac{p_{0}}{4 r_{f}}$ according to [60], by considering a maximum inflating pressure $p_{0, \max }$ of 8 bar. Noticeably, such design parameter is $160 \%$ of the nominal inflating pressure of the tire and is chosen as a compromise between safety, mass, and rolling resistance reduction [61].

\subsection{Materials and stacking sequence constraints}

As previously mentioned in Section 3, among the marketavailable FRP materials, CFRP ones have been chosen for the design of the wheel. Both fabric and unidirectional (UD) CFRP prepregs were adopted. Two types of UD carbon fibers have been selected: high modulus (HM) and high strength (HS). The first type of fibers has been used to increase, where necessary, the stiffness of the component, while the second type to increase the safety. Moreover, a resin with good performances at high temperature combined with good impact 


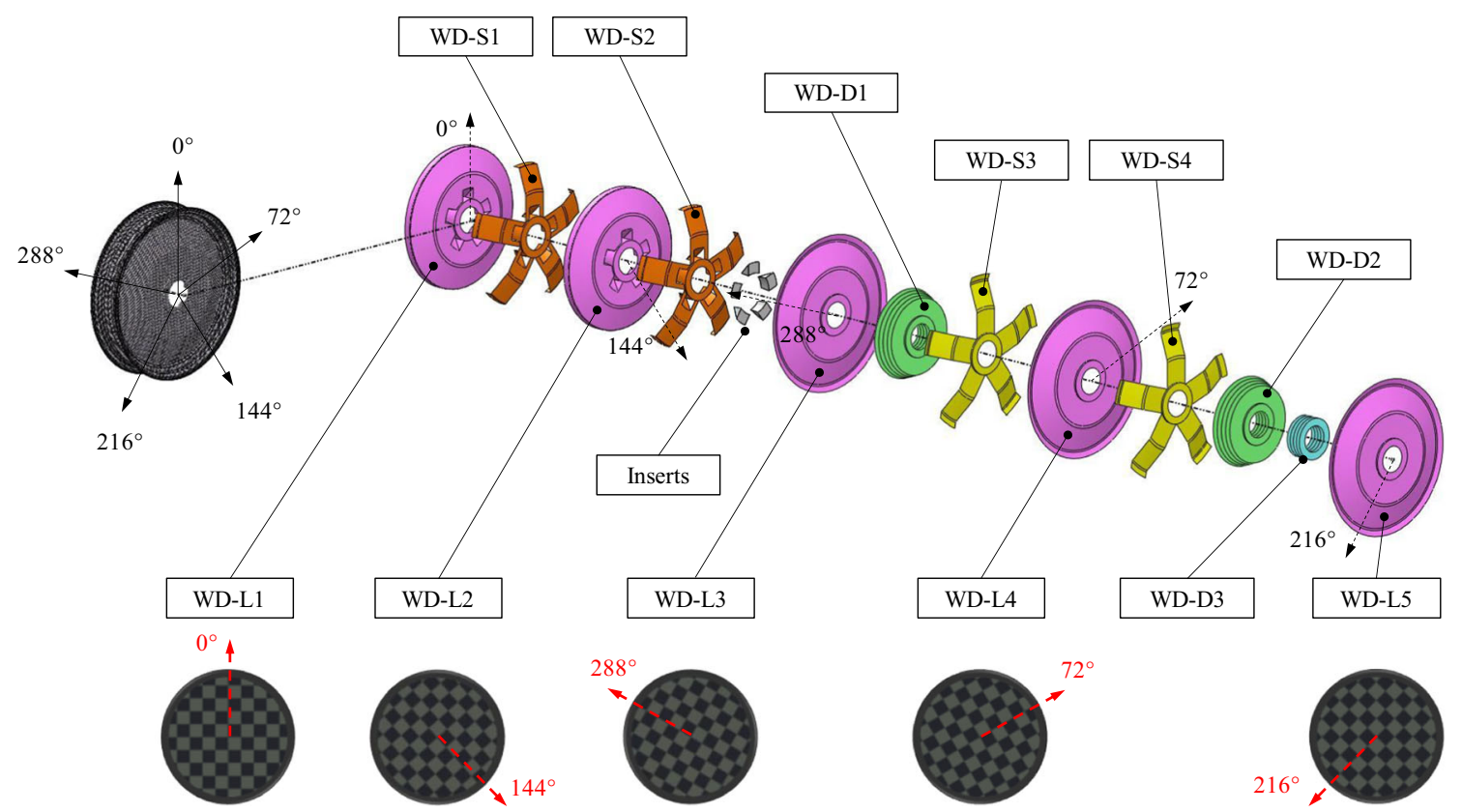

Fig. 8 Schematic representation of wheel disk stacking sequence. Purple: 5 lens units (from WD-L1 to WD-L5). Orange: rear UD spokes groups reinforcement (WD-S1 and WD-S2). Yellow: frontal UD spokes groups reinforcement (WD-S3 and WD-S4). Green: central discs groups reinforcements (from WD-D1 to WD-D2). Blue: discs group reinforcement for the hub connection (WD-D3). Gray: 5 nose inserts resistance was selected. Specifically, the prepregs used are a $200 \mathrm{~g} / \mathrm{m}^{2} 2 \times 2$ twill fabric with $6 \mathrm{~K}$ T800HB fibers MTM493/CF1218-42\%RW, a $124 \mathrm{~g} / \mathrm{m}^{2}$ UD with $12 \mathrm{~K}$ HS T1000 fibers MTM49-3/T1000G(12K)-124-36\%RW, and a $124 \mathrm{~g} /$ $\mathrm{m}^{2}$ UD with 12K HM M46J fibers MTM49-3/M46J(12K)124-36\%RW), supplied by Solvay Cytec Industries Inc. All material properties, resulting from datasheet and experimental characterization program [62], are summarized in Table 3.

A preliminary design in terms of shape and layup was defined. Shape was drawn on the result of the conceptual design phase to accomplish the geometrical constraints described in Fig. 3. Number of spokes was set to 5 as a

Table 3 Carbon fiber prepreg properties

\begin{tabular}{lllll}
\hline & T800 Twill & T1000 UD & M46J UD & \\
\hline $\mathrm{E}_{1}$ & 66.0 & 155 & 235 & $\mathrm{GPa}$ \\
$\mathrm{E}_{2}$ & 66.0 & 6.8 & 6.9 & $\mathrm{GPa}$ \\
$\mathrm{G}_{12}$ & 4.4 & 3.1 & 4.1 & $\mathrm{GPa}$ \\
$\gamma_{12}$ & 0.06 & 0.32 & 0.32 & - \\
$\sigma_{\mathrm{t} 1}$ & 852 & 2999 & 1709 & $\mathrm{MPa}$ \\
$\sigma_{\mathrm{t} 2}$ & 852 & 19.3 & 25.8 & $\mathrm{MPa}$ \\
$\sigma_{\mathrm{c} 1}$ & 605 & 1431 & 875 & $\mathrm{MPa}$ \\
$\sigma_{\mathrm{c} 2}$ & 605 & 199 & 189 & $\mathrm{MPa}$ \\
$\tau_{12}$ & 123 & 132 & 69 & $\mathrm{MPa}$ \\
$\mathrm{ILSS}$ & 78.3 & 105 & 88.2 & $\mathrm{MPa}$ \\
\hline
\end{tabular}

compromise between radial compliance, bending stiffness, and processability.

The layup was subdivided in different zones, each one with a preferential fiber orientation, to withstand a specific load direction. Indeed, UD was oriented in radial direction to bear bending and radial loads while fabrics, oriented to form a quasi-isotropic laminate, were introduced to bear the torque.

The stacking sequence of the wheel disk is schematically represented in Fig. 8. Three composite units have been used to laminate the wheel disc (WD): the lens unit (WD-L), the spokes group unit (WD-S), and the reinforcing disc unit (WD-D). In particular, 5 lens units, each of them made with a single-fabric ply (from WD-L1 to WD-L5), were interleaved with 4 spokes groups (from WD-S1 to WD-S4), whose number of plies has subjected to optimization, together with 3 reinforcing fabric disks groups (from WD-D1 to WD-D3), placed in the central part of the wheel disk.

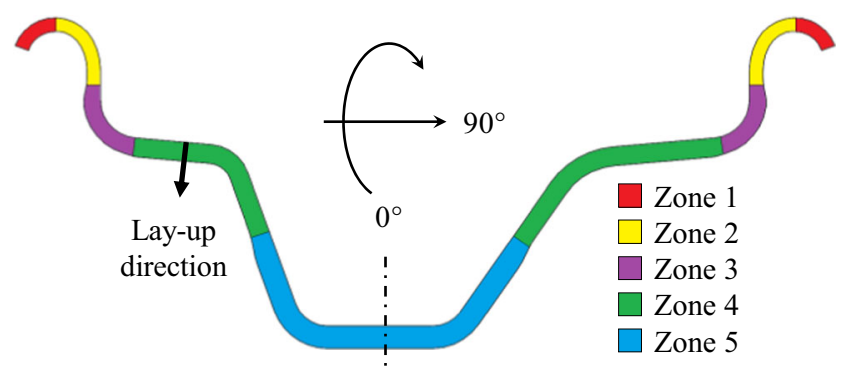

Fig. 9 Ideal subdivision of the rim for stacking sequence optimization 
Orientation angle of each ply of the series from WD-L1 to WD-L5 and from WD-D1 to WD-D3, with respect to the next, was set at $144^{\circ}$, in order to have at least one fabric aligned to each spoke and globally obtain a quasi-isotropic laminate. Moreover, by interleaving UD with fabric, it is possible to limit the thickness of each UD group, so as to improve the quality of the layup, by reducing fiber waviness and by stopping through the thickness crack propagation. Therefore, variables of the optimization process for the wheel disk are material and number of the UD plies for each spokes group.

In the same way, as depicted in Fig. 9, the rim layup was subdivided into 5 regions, symmetric about the represented vertical axis. The initial stacking sequence for DOE involved a fraction of UD HS, for safety issue, mainly oriented at $90^{\circ}$, interleaved with fabric plies to reduce and limit crack propagation. Variables of the optimization process for the rim are number, orientation, and positioning within the laminate of UD and fabric plies.

\subsection{Numerical model}

The wheel is modeled in ANSYS Workbench and ACP using 4 nodes shell-layered elements (SHELL181) with an average element size of $1.2 \mathrm{~mm}$. The model consisted of $1,420,000$ degrees of freedom, and the linear static analysis was solved by a direct method. Mesh, load application, and constraints for the 3 loading conditions, discussed in Paragraph 5.1, are shown in Fig. 10. From preliminary investigations, bending load case was found to be the most severe for the wheel. Optimizations were therefore performed under loading condition expressed by Eq. (1) combined with maximum inflating pressure, and the final solution was verified to withstand in both torque and rolling.

\subsection{Geometry optimization}

A critical point of the proposed conceptual solution could be the value of the angle $\alpha$ shown in Fig. 11. For this reason, finite element (FE) analysis were performed on different angle configurations of the wheel disk under bending load, in order to minimize deformation and Inverse Reserve Factor (IRF) index, based on Tsai-Wu failure criterion. The investigation was performed between $16^{\circ}$ and $36^{\circ}$. The lower value was chosen according to geometrical constraints, while the upper one was selected as a limit to avoid both the risk of prepreg wrinkling during draping both fiber damages during curing

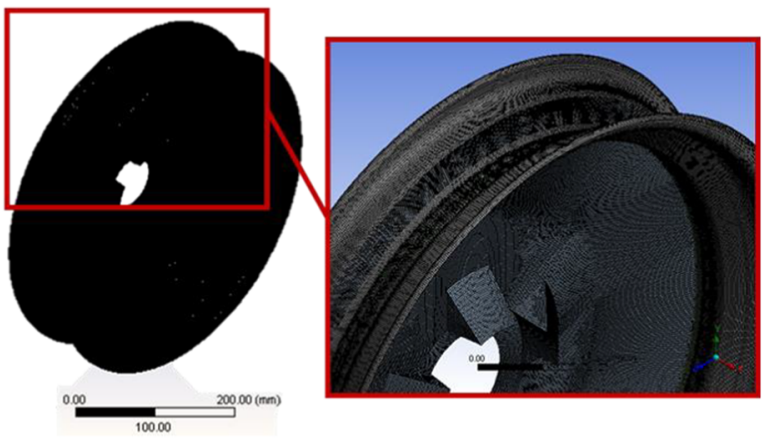

(a)

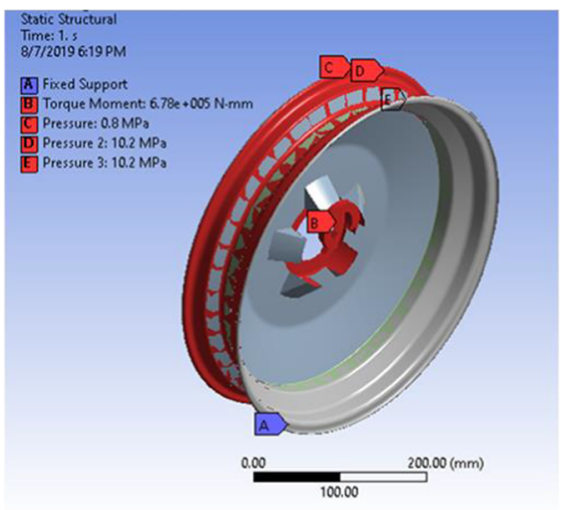

(c)

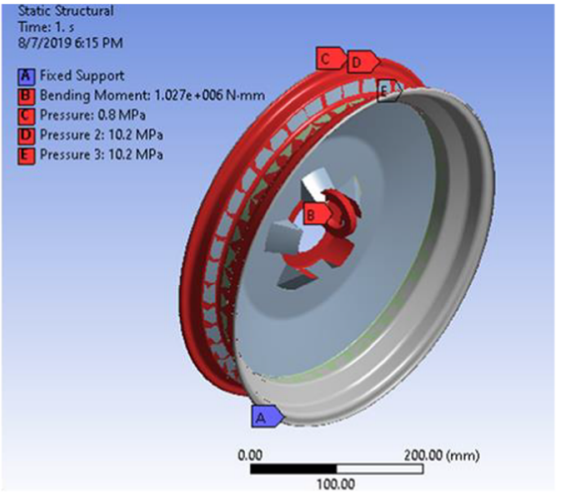

(b)

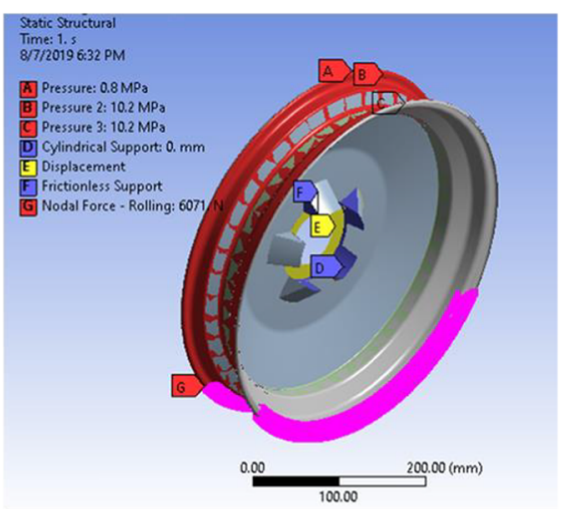

(d)

Fig. 10 Numerical model of the wheel. a Mesh. b Bending load case. $\mathbf{c}$ Torque load case. $\mathbf{d}$ Rolling load case 

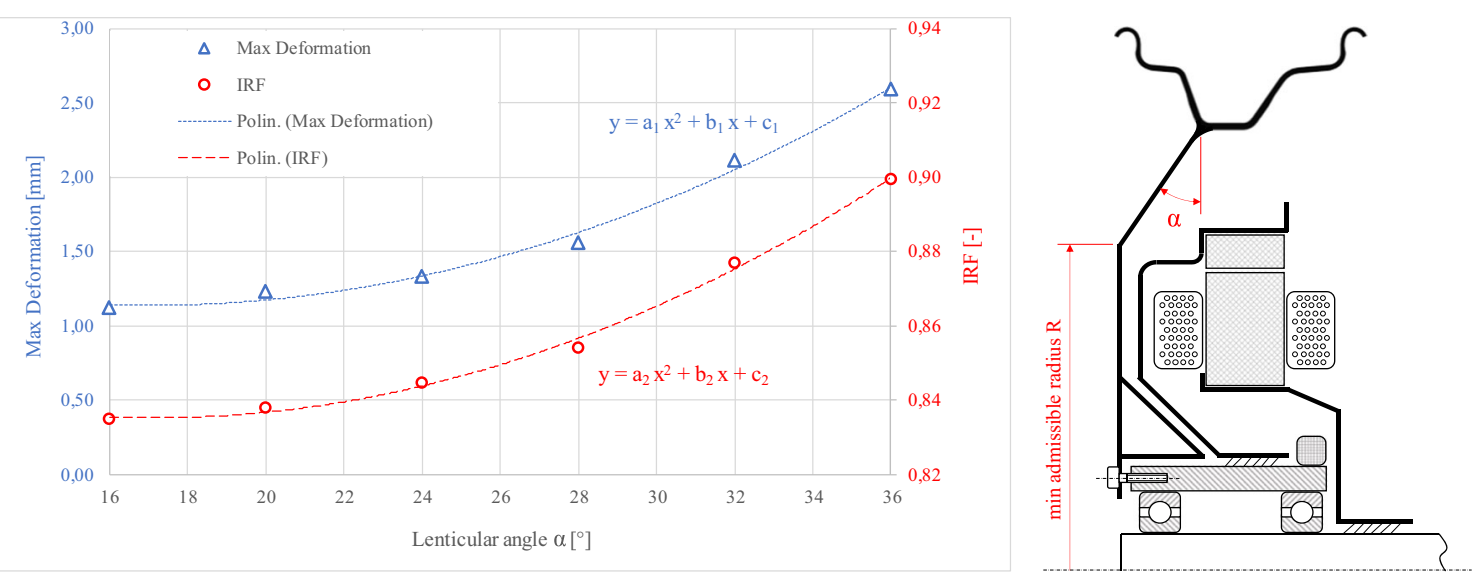

Fig. 11 Maximum deformation and Tsai-Wu IRF on the wheel disk for different $\alpha$ angle configuration under bending load $\left(a_{1}=0.0041, b_{1}=-0.1384\right.$, $c_{1}=2.3144, R_{1}^{2}=0.99 . a_{2}=0.0002, b_{2}=-0.0062, c_{2}=0.8881, R_{2}^{2}=0.99$ )

process [63]. As shown in Fig. 11, reducing the angle, both deflection and failure index decreases asymptotically. Therefore, an angle of $20^{\circ}$ was chosen, which is the minimum admissible value to prevent the risk of interference between the wheel disk profile and the rotor.

\subsection{Stacking sequence optimization}

The optimization process of a composite structure is dominated by one or more objective functions, design variables, and constraints [64-66]. In this work, the minimization of the Tsai-Wu IRF, combined with the minimization of weight and deflection, was considered.

Stacking sequence was optimized in Ansys Workbench by means of DOE. Screening algorithm, based on Shifted Hammersley Sampling Method, was adopted as a strategy for the optimization, due to its ability to deal with a high number of input parameters [67]. Unfortunately, as often happens for a complex stacking sequence, it was impossible to successfully perform a direct optimization, due to the high number of input parameters. Therefore, DOE output data were considered to graphically identify local minima and find the best candidate solution.

Output design variables for both rim and wheel disk are shown in Fig. 12, in which all candidate design points (DPs) are represented. Feasible and unfeasible DPs were judged considering separately DOE constrains for the rim and wheel disk, in order to investigate other DP combinations not contemplated by the algorithm. In particular, as DOE constrains, it was assumed a maximum allowable IRF of 1 for the wheel disk, to maximize the strength/mass ratio, while an IRF of 0.5 was chosen for the rim to avoid matrix cracking that can cause undesirable pressure losses.

Therefore, feasible DP for the wheel disk $(\mathrm{IRF}<1)$ and for the rim $(\mathrm{IRF}<0.5)$ are plotted in Fig. 13 as function of IRF, deformation, and mass. Dots highlighted in gray represent the best candidate solutions found automatically by the software. However, by the separate analysis for the wheel disk and the rim, it was possible to graphically identify a lighter solution thanks to the combination of the best stacking sequence of each separate component.

Interestingly, this solution presents HM UD fibers positioned on the external layers of the laminate (WD-S1 and

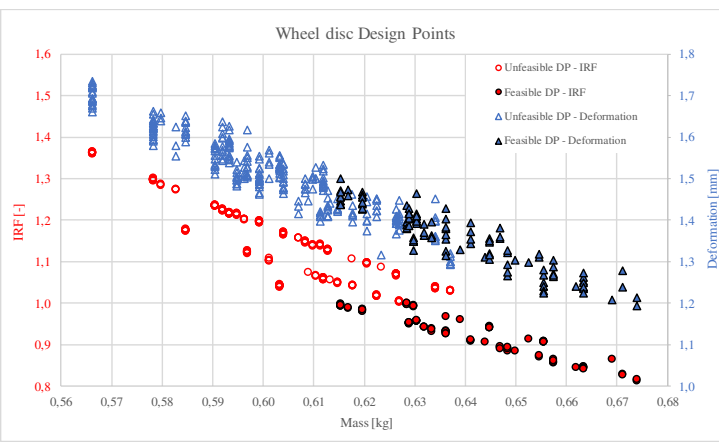

(a)

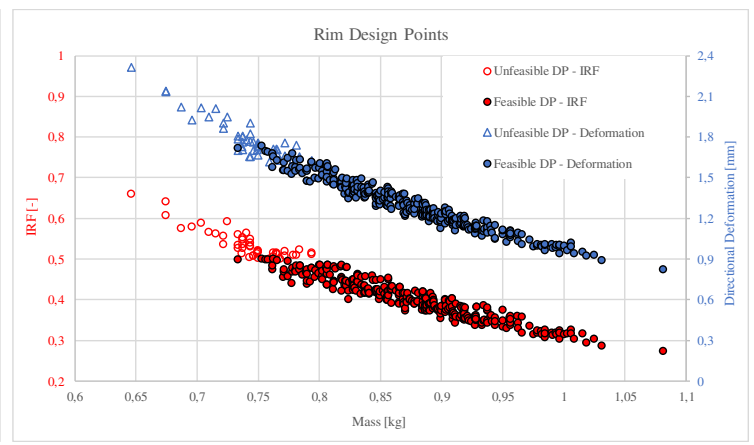

(b)

Fig. 12 DOE candidate design points for both $\mathbf{a}$ wheel disk and $\mathbf{b}$ rim 


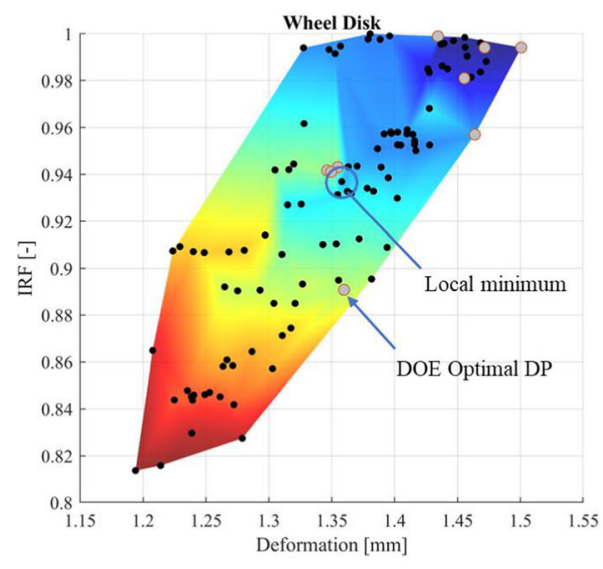

(a)

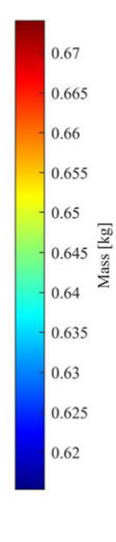

Fig. 13 Tsai-Wu IRF, deformation, an mass of the feasible design points com

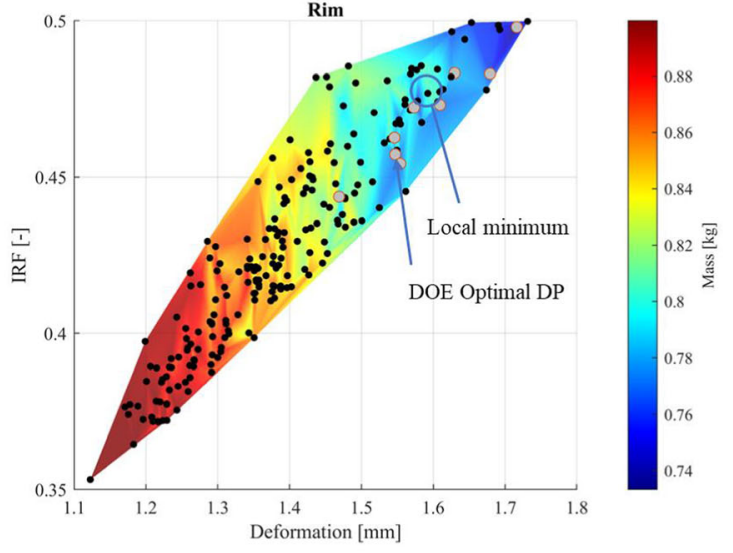

(b)
WD-S4) and HS UD fibers in the inner groups (WD-S2 and WD-S3). Moreover, this configuration provides an increased bending stiffness thanks to the external layers, combined with a good strength due to the presence of HS UD in the inner groups of the laminate. The best solution for the rim evidenced a stacking sequence having UD plies positioned on the external layers, to increase the section modulus, and fabric plies in the centerline.

Thanks to the proposed approach, it was possible to reduce the overall mass of the wheel of $16.7 \%$, compared to the preliminary proposed stacking sequence. The final masses of the rim and wheel disk were estimated to be $0.76 \mathrm{~kg}$ and $0.63 \mathrm{~kg}$ respectively, resulting in a total estimated wheel weight of $1.39 \mathrm{~kg}$.

FEA results represented in Fig. 14 show that the optimized wheel is able to withstand at all 3 design loading conditions, and no critical areas are evidenced. Optimized laminations for both wheel disk and rim are reported in the Supplementary Information (SI2 and SI3 respectively).

In order to verify the effectiveness of the optimized CFRP wheel, an aluminum one was designed (see Supplementary Information - SI4). The aluminum wheel was developed following the same requirements and constrains defined in the conceptual design phase for the composite wheel. It is interesting to mention that the final weight of the aluminum wheel was $2.86 \mathrm{~kg}$, corresponding to an increment of $51.2 \%$ with respect to the optimized CFRP wheel, thus, confirming the effectiveness of the CFRP-based solution.

\section{Manufacturing}

A specific mold was developed for the manufacturing of the optimized wheel. The mold consists of 4 parts as evidenced in

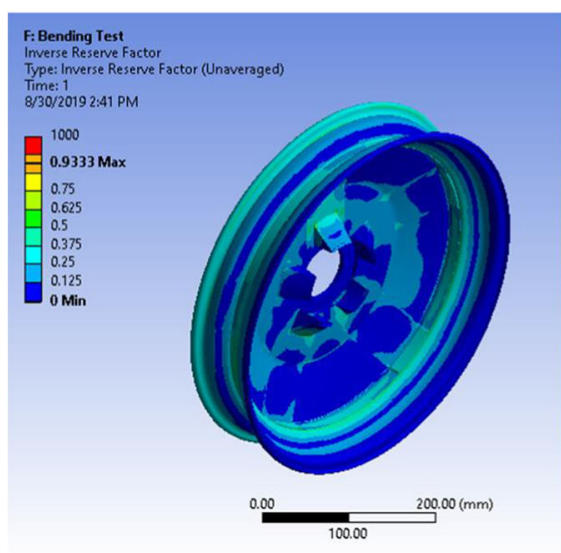

(a)

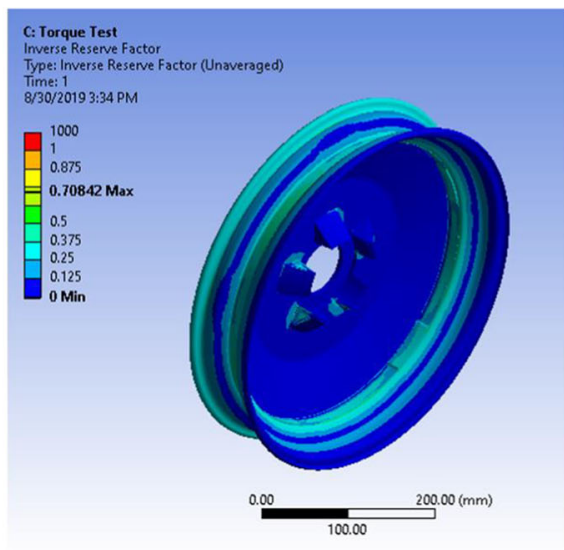

(b)

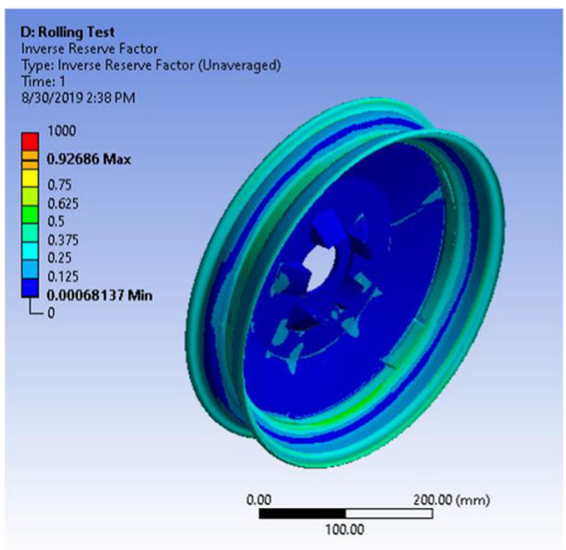

(c)

Fig. 14 Tsai-Wu IRF distribution obtained from FEA of the optimized wheel under prescribed load cases a bending, $\mathbf{b}$ torque, and $\mathbf{c}$ rolling combined with inflating pressure 


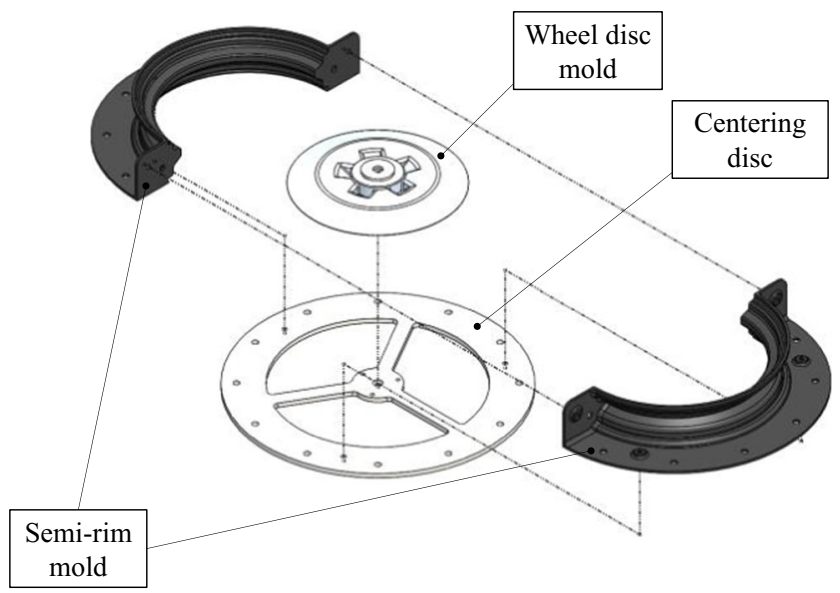

Fig. 15 Scheme of the mold assembly

Fig. 15. As a first step, shown in Fig. 16a, the two CFRP parts of the mold of the rim were assembled, release agent was applied, and prepreg was stacked directly on the mold according to the optimal sequence obtained by FEA. As a second step, shown in Fig. 16b, the rim assembly was fixed on a centering disk to match under strict dimensional tolerances with the mold of the wheel disk. Finally, as shown in Fig. 16c, optimal stacking sequence for the wheel disk was stacked on its mold to obtain the best calculated performances. The final vacuum built-up was cured for $90 \mathrm{~min}$ in autoclave at a temperature of $140{ }^{\circ} \mathrm{C}$ and a pressure of 6 bar. The final weight of the wheel was $1.41 \mathrm{~kg}$, in accordance with the prevision given by the model.

\section{Experimental validation}

Complete wheel assembly has been tested in rotating fatigue bending using the custom device represented in Fig. 17. The equipment consisted of a basement (a) fixed to the ground, a rotating disc (b) with 8 fixing for the rim (c), a steel tube (d) connected to the center of the wheel disk, and a movable mass (e) for adjusting the applied bending moment.

Since only one sample was available, a custom incremental load fatigue test, inspired to the Locati test [68, 69], was performed at a rotational frequency of $0.5 \mathrm{~Hz}$. The wheel was gradually loaded until its failure: cycles and applied loads are summarized in Table 4. Due to the effect that the wheel has been designed for racing, the number of incremental fatigue cycles was reduced with respect to what is commonly adopted in literature.

At the end of each load step, testing device was stopped at a prescribed angular position and deflection at the tip of the tube (d) was measured. Angular position was chosen to maximize strain on the surface, i.e., when the bending moment is applied between two spokes.

A digital image correlation (DIC) analysis was performed by means of a 3D DIC system (Q-400, Dantec Dynamics), equipped with 5 Megapixels cameras and $17 \mathrm{~mm}$ lenses [70]. A speckle pattern was previously applied on the wheel disk surface by means of an airbrush. Istra-4D software (Dantec Dynamics) was employed to elaborate the captured images and calculate the strain field of the wheel disk. Facet size and grid spacing was set to 19 and 11 pixels respectively, and a local regression displacement smoothing filter of $25 \times$ 25 facets, available within Dantec software, was applied as a compromise between accuracy and spatial resolution $[71,72]$.

In order to validate the numerical model in the elastic field, the strain distribution of the FE model was compared with DIC results. In Fig. 18 is reported the strain field at the end of load step 4 , which corresponds to the $50 \%$ of the design bending moment. The zone of analysis, between a radius of $75 \mathrm{~mm}$ and $120 \mathrm{~mm}$, corresponds to the most stressed part of the wheel disk. An evaluating path was applied along a spoke (R1) and another one between two spokes (vertical). Since the component is loaded symmetrically with respect to the vertical path, only the R1 spoke path results have been reported.

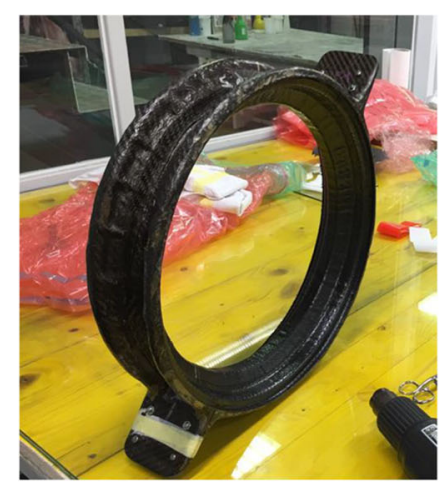

(a)

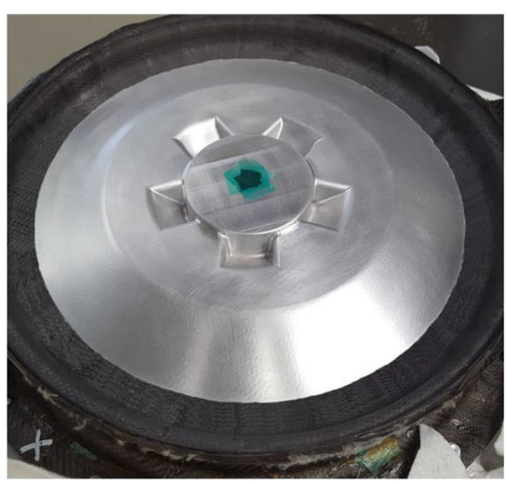

(b)

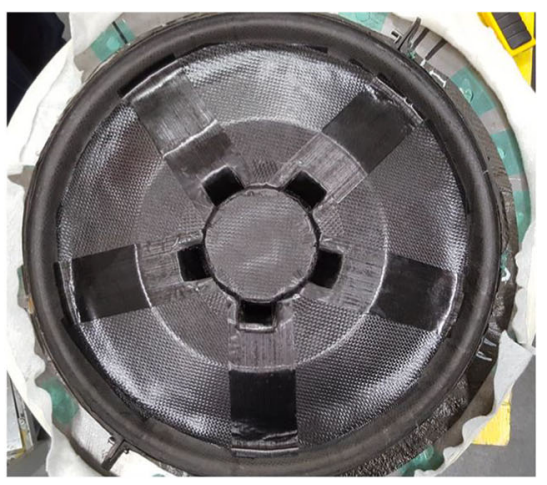

(c)

Fig. 16 Manufacturing of the CFRP wheel. a Rim. b Rim and wheel disk mold assembled. $\mathbf{c}$ Stacking process of wheel disk 

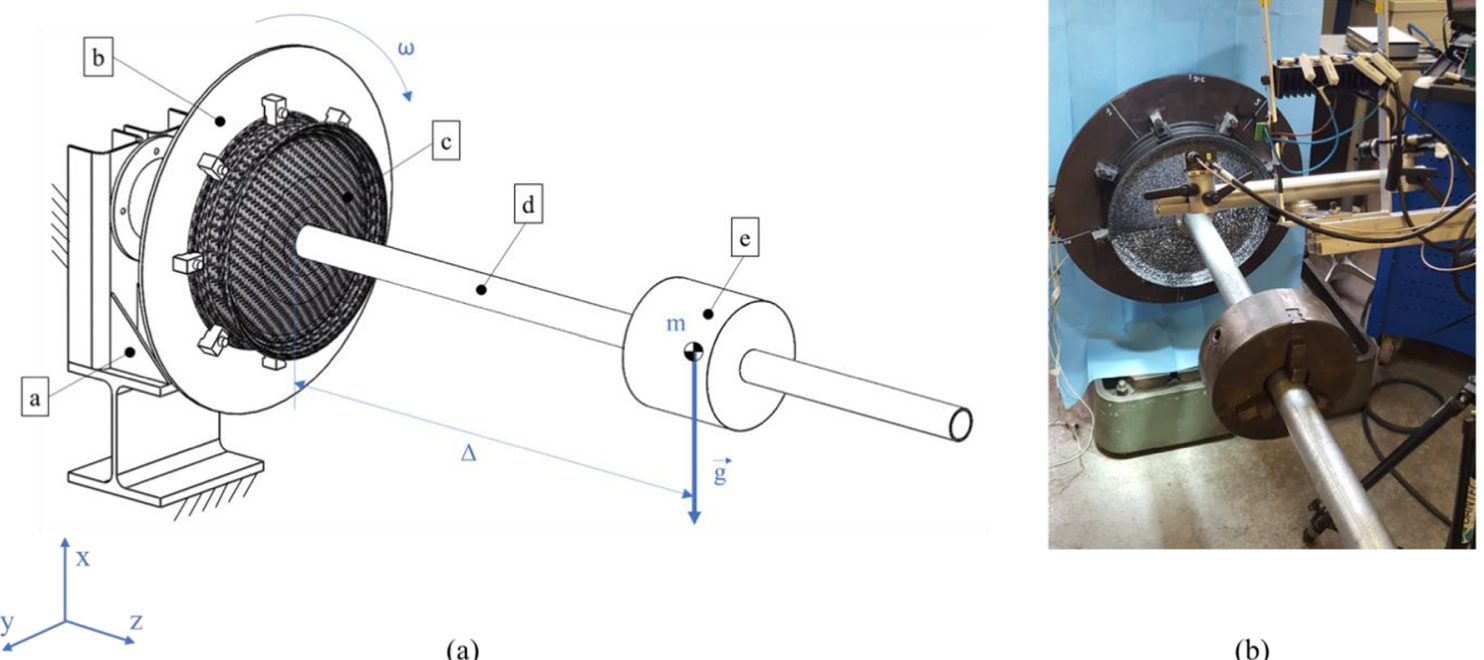

(a)

(b)

Fig. 17 Experimental setup. a Schematics of the fatigue test bench. b Test bench with 3D DIC system

Table 4 Load steps for experimental test under bending moment

\begin{tabular}{lclc}
\hline Load step & No. of cycles & $\% \mathrm{M}_{\mathrm{b}, \max }$ & $\mathrm{M}_{\mathrm{b}}(\mathrm{Nm})$ \\
\hline LS1 & 1000 & $20 \%$ & 205 \\
LS2 & 800 & $30 \%$ & 308 \\
LS3 & 600 & $40 \%$ & 411 \\
LS4 & 400 & $50 \%$ & 514 \\
LS5 & 200 & $60 \%$ & 616 \\
LS6 & 100 & $70 \%$ & 719 \\
LS7 & 50 & $90 \%$ & 924 \\
\hline
\end{tabular}

In Fig. 19 are represented the strain distributions along the aforementioned paths. The blue lines represent the experimental DIC results, while the red ones the numerical FE model results. The radial and hoop strains for the $\mathrm{R} 1$ spoke path are reported in Fig. 19a and b while for the vertical path are plotted in Fig. 19c and d respectively.

As can be observed, the numerical and experimental curves exhibit the same trend. Regarding the spoke path, maximum

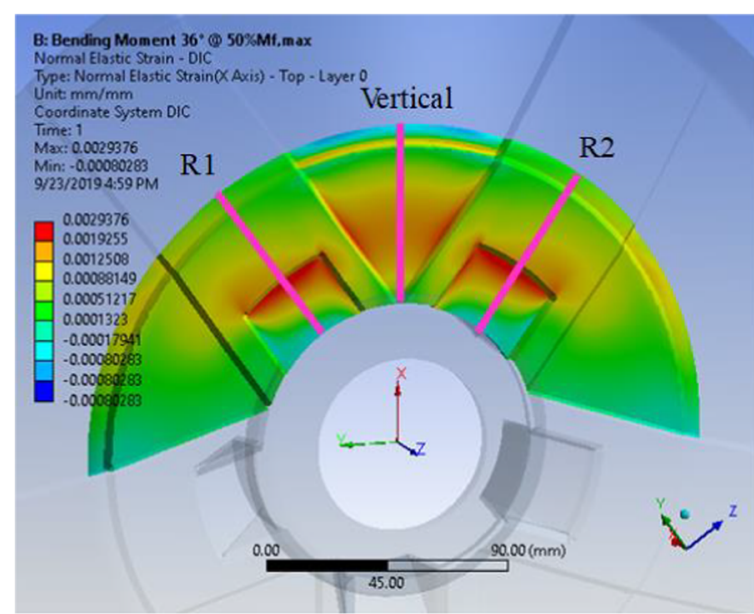

(a)

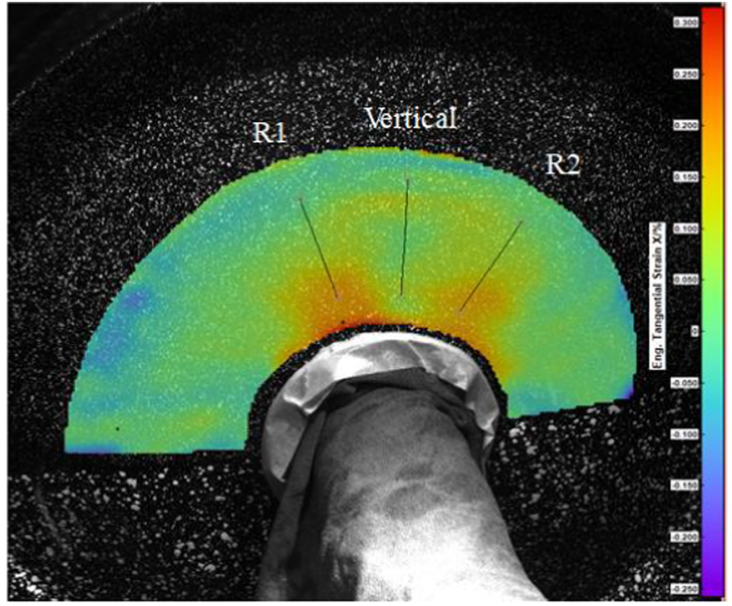

(b)

Fig. 18 Elastic strain distribution for load step 4 and evaluating paths. a FEA results. b DIC results 
R1 spoke path

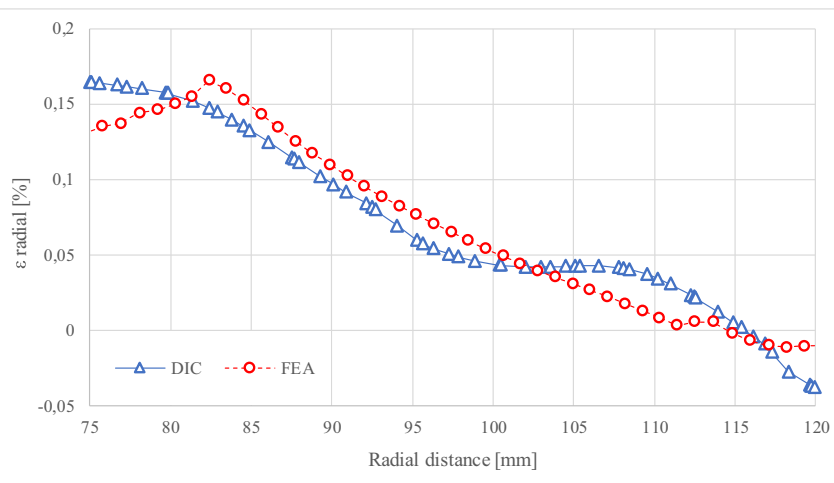

(a)

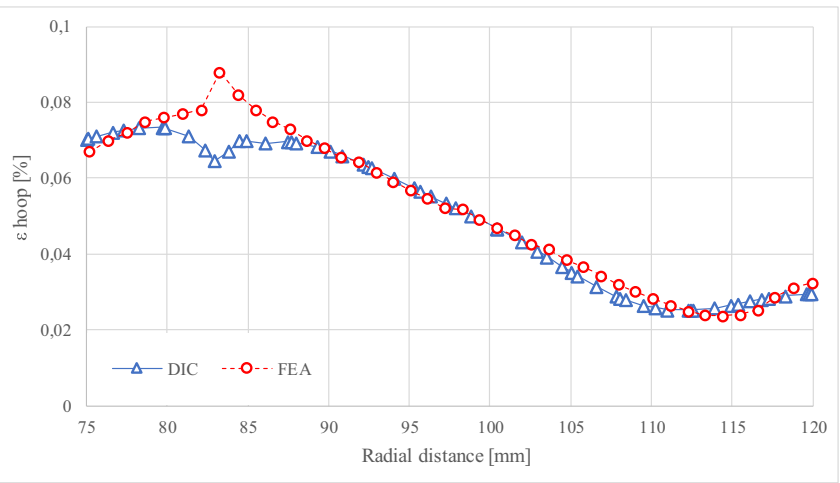

(b)

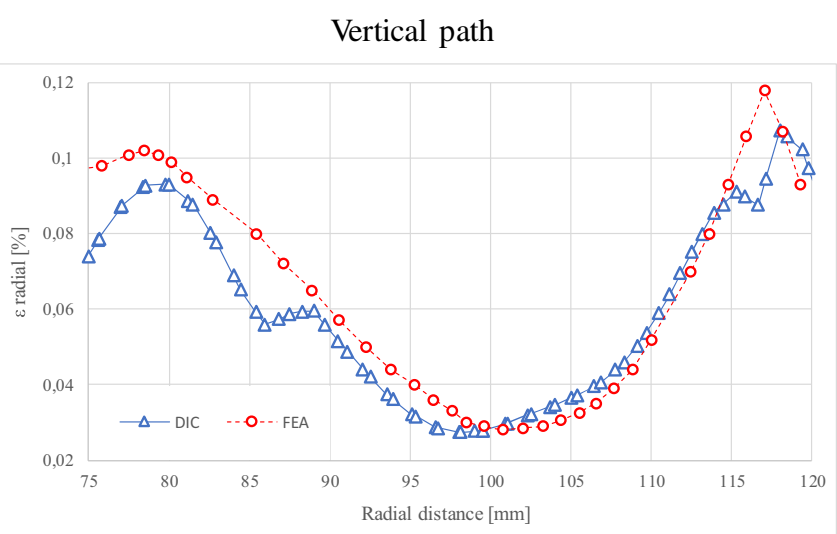

(c)

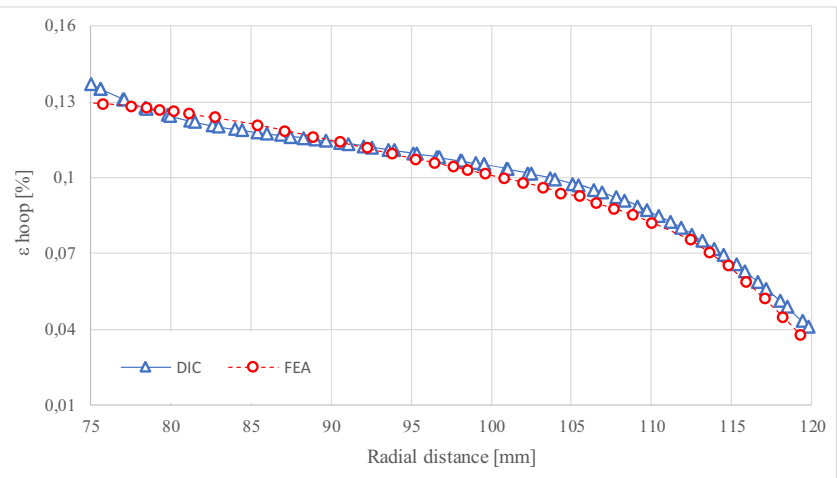

(d)

Fig. 19 Strain comparison between DIC and FEA on load step 4. a Radial strain distribution along R1 path. b Hoop strain distribution along R1 path. $\mathbf{c}$ Radial strain distribution along Vertical path. d Hoop strain distribution along vertical path

discrepancies of $19 \%$ and $21 \%$ for the radial and hoop strains were respectively revealed. Interestingly, these maximum errors occurred at the transition zone between the nose and the rest of the wheel disk laminate, due to the simplifications introduced in the numerical model, thus leading in local strain concentration phenomena.

Similarly, for the vertical path, a maximum relative error of $23 \%$ for the radial strain was measured. This error, instead, occurred at the edge of the reinforcement disks (WD-D series), where there is an important change in thickness. Indeed, the shell model is not able to correctly represent the strain field in the drop-off zone, as it does not take into account out-of-plane loads [73].

Results of fatigue test are reported in Fig. 20. To evaluate the structural integrity of the wheel, an index related to the component flexural stiffness and the applied bending moment was introduced as follows: flexural stiffness index $=[$ bending moment] / [tube tip displacement]. The flexural stiffness index
Fig. 20 Fatigue test results: comparison between applied bending moment and flexural stiffness index versus load steps

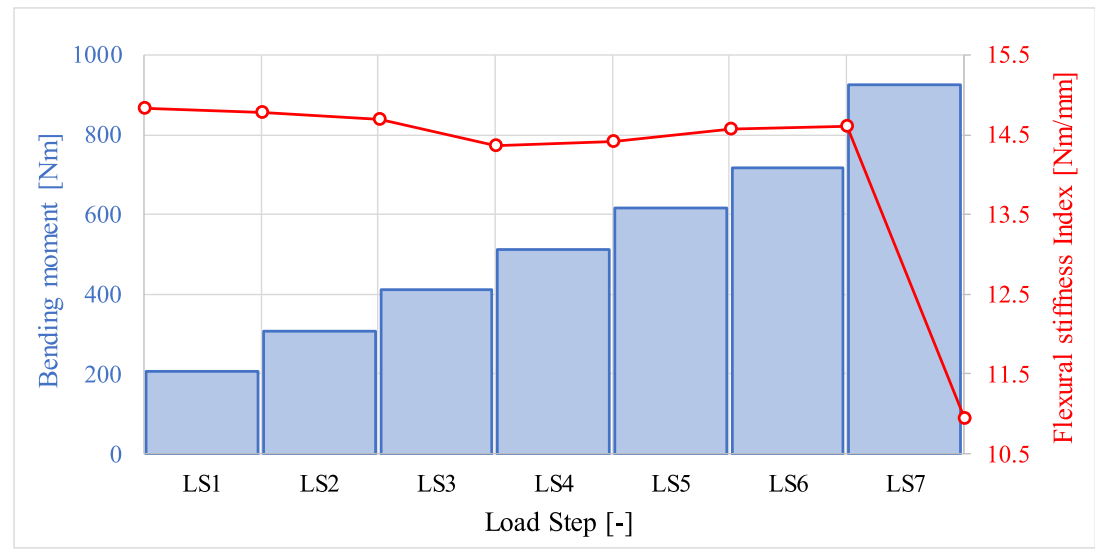


behavior was constant until the end of LS6, which corresponds to the $70 \%$ of the design bending moment. During LS7, when the $90 \%$ of the design bending moment was applied, multiple and continuous audible cracks happened and after 50 cycles, the flexural stiffness index decreased down to $34 \%$ of the initial value of the flexural stiffness index.

\section{Conclusions}

In this work, the systematic design approach has been extended to the design of composite components and successfully applied to the case of the CFRP motor wheel of the Emilia 4 solar vehicle. The proposed approach is intuitive, and it enables the designers to account for the effect of material, and the related manufacturing processes, through the entire design process. This fact has remarkable consequences because it allows building effective and sometimes very advanced conceptual design solutions, including also innovative functions thanks, for example, to the use of smart materials. Moreover, the new methodology allows reliable identification of the best design solution thanks to the statistical analysis of the evaluation made by a panel of experts external to the design team. Finally, this material-oriented approach integrates the optimization of both geometry and materials respecting, at the same time, the requirements and constraints of the project. In particular, optimization of geometry, material, and stacking sequence was applied to the CFRP wheel and it was performed using DOE, resulting in a weight saving of $16.7 \%$ with respect to the initial CFRP solution and $51.2 \%$ with respect to the best aluminum solution. Following the approach, the studied wheel was successfully manufactured and tested both statically and under bending fatigue. In particular, strain fields measured with a 3D DIC system during static tests were in good accordance with numerical results. Fatigue test showed that until the $90 \%$ of the design bending moment, the flexural stiffness index of the component was maintained. All these facts supported the conclusion that the proposed systematic material-oriented design approach is an effective methodology for the design of composite components and systems. Besides, this systematic approach can also be used to design and discover new materials which can integrate novel architecture and advanced features (e.g., damping, toughening, sensing, diagnostics, healing, and others).

Acknowledgments They wish to acknowledge the graduate student Alejandro Bobes de Jesús for his help with the project, and they also would like to express their appreciation to Onda Solare Team and Mauro Sassatelli of Metal T.i.g. Srl for several very helpful discussions and the wheels production.

Funding information Open access funding provided by Alma Mater Studiorum - Università di Bologna within the CRUI-CARE Agreement. The project "TEAM SAVE_E91B18000460007" (PG/2018/632196) of framework POR FESR 2014-2020 funded by Regione Emilia Romagna with DGR 986/2018 provided financial support.

Data availability All data needed to evaluate the conclusions in the paper are present in the paper and/or the Supplementary Information. Additional data related to this paper are available from the corresponding authors upon reasonable requests.

Open Access This article is licensed under a Creative Commons Attribution 4.0 International License, which permits use, sharing, adaptation, distribution and reproduction in any medium or format, as long as you give appropriate credit to the original author(s) and the source, provide a link to the Creative Commons licence, and indicate if changes were made. The images or other third party material in this article are included in the article's Creative Commons licence, unless indicated otherwise in a credit line to the material. If material is not included in the article's Creative Commons licence and your intended use is not permitted by statutory regulation or exceeds the permitted use, you will need to obtain permission directly from the copyright holder. To view a copy of this licence, visit http://creativecommons.org/licenses/by/4.0/.

\section{References}

1. IEA (2012) Fuel economy of road vehicles. IEA Technology Roadmaps. https://doi.org/10.1787/9789264185029-en

2. ITF (2017) Lightening up: how less heavy vehicles can help cut $\mathrm{CO} 2$ emissions. International Transport Forum Policy Papers. https://doi.org/10.1787/ecf5b956-en

3. IEA (2019) Material efficiency in clean energy transitions. IEA. https://doi.org/10.1787/aeaaccd8-en

4. Sapuan SM, Mansor MR (2014) Concurrent engineering approach in the development of composite products: a review. Mater Des 58: 161-167. https://doi.org/10.1016/j.matdes.2014.01.059

5. Aceves CM, Skordos AA, Sutcliffe MPF (2008) Design selection methodology for composite structures. Mater Des 29(2):418-426. https://doi.org/10.1016/j.matdes.2007.01.014

6. Ashby MF, Johnson K (2013) Materials and design: the art and science of material selection in product design, $3 \mathrm{rd}$ edn. Butterworth-Heinemann, Oxford

7. Pahl G, Beitz W, Feldhusen J, Grote KH (2007) Engineering design: a systematic approach, 3rd edn. Springer, London

8. Rao YS, Mohan NS, Shetty N, Shivamurthy B (2019) Drilling and structural property study of multi-layered fiber and fabric reinforced polymer composite - a review. Mater Manuf Process 34(14):15491579. https://doi.org/10.1080/10426914.2019.1686522

9. Kaybal HB, Ünüvar A, Koyunbakan M, Avc1 A (2019) A novelty optimization approach for drilling of CFRP nanocomposite laminates. Int J Adv Manuf Technol 100(9-12):2995-3012. https://doi. org/10.1007/s00170-018-2873-1

10. Hassan MH, Othman AR, Kamaruddin S (2017) A review on the manufacturing defects of complex-shaped laminate in aircraft composite structures. Int J Adv Manuf Technol 91(9-12):4081-4094. https://doi.org/10.1007/s00170-017-0096-5

11. Heslehurst RB (2014) Defects and damage in composite materials and structures. CRC Press, Taylor \& Francis Group, Boca Raton

12. Brinksmeier E, Fangmann S, Rentsch R (2011) Drilling of composites and resulting surface integrity. CIRP Ann Manuf Technol 60(1):57-60. https://doi.org/10.1016/j.cirp.2011.03.077

13. Tsao CC, Hocheng H (2007) Effect of tool wear on delamination in drilling composite materials. Int J Mech Sci 49(8):983-988. https:// doi.org/10.1016/j.ijmecsci.2007.01.001 
14. Persson E, Eriksson I, Zackrisson L (1997) Effects of hole machining defects on strength and fatigue life of composite laminates. Compos A: Appl Sci Manuf 28(2):141-151. https://doi.org/10. 1016/S1359-835X(96)00106-6

15. Camanho PP, Matthews FL (1997) Stress analysis and strength prediction of mechanically fastened joints in FRP: a review. Compos A: Appl Sci Manuf 28(6):529-547. https://doi.org/10. 1016/S1359-835X(97)00004-3

16. Thoppul SD, Finegan J, Gibson RF (2009) Mechanics of mechanically fastened joints in polymer-matrix composite structures - a review. Compos Sci Technol 69(3-4):301-329. https://doi.org/10. 1016/j.compscitech.2008.09.037

17. Gamdani F, Boukhili R, Vadean A (2015) Tensile strength of openhole, pin-loaded and multi-bolted single-lap joints in woven composite plates. Mater Des 88:702-712. https://doi.org/10.1016/j. matdes.2015.09.008

18. Meram A, Can A (2019) Experimental investigation of screwed joints capabilities for the CFRP composite laminates. Compos Part B 176:107142. https://doi.org/10.1016/j.compositesb.2019. 107142

19. Abdullah MS, Abdullah AB, Hassan MH, Samad Z (2018) Bearing strength and progressive failure analysis of the punched hole of CFRP under tensile loading. Int J Adv Manuf Technol 97(5-8): 2163-2171. https://doi.org/10.1007/s00170-018-2091-x

20. Banea MD, Da Silva LFM (2009) Adhesively bonded joints in composite materials: an overview. Proc Inst Mech Eng L J Mater Des Appl 223(1):1-18. https://doi.org/10.1243/ 14644207JMDA219

21. Budhe S, Banea MD, de Barros S, da Silva LFM (2017) An updated review of adhesively bonded joints in composite materials. Int $\mathrm{J}$ Adhes Adhes 72:30-42. https://doi.org/10.1016/j.ijadhadh.2016. 10.010

22. Barbero EJ (2017) Introduction to composite materials design, 3rd edn. CRC Press, Taylor \& Francis Group, Boca Raton

23. Sridharan S (2008) Delamination behaviour of composites. Woodhead Publishing Limited, Cambridge

24. Talreja R, Singh CV (2012) Damage and failure of composite materials. Cambridge University Press, Cambridge

25. Talreja R, Varna J (2015) Modeling damage, fatigue and failure of composite materials. Woodhead Publishing, Cambridge

26. Kaspar J, Vielhaber M (2017) Fiber-reinforced composite design within a lightweight and material-oriented development process. In: DS 87-1 Proceedings of the 21st International Conference on Engineering Design (ICED 17) Vol 1: Resource Sensitive Design, Design Research Applications and Case Studies, Vancouver, Canada, 21-25.08. 2017. pp 329-338

27. Mastura MT, Sapuan SM, Mansor MR, Nuraini AA (2017) Conceptual design of a natural fibre-reinforced composite automotive anti-roll bar using a hybrid approach. Int J Adv Manuf Technol 91(5-8):2031-2048. https://doi.org/10.1007/s00170-016-9882-8

28. Ashby M (2011) Materials selection in mechanical design, 4th edn. Butterworth-Heinemann, Oxford

29. Ashby MF, Cebon D (2007) Teaching engineering materials: the CES EduPack. In: Engineering Department, Cambridge University, England. Retrieved June 1, 2015, from http://web.mit.edu/course/3/3. 225/refs/Teaching_Engineering_Materials.pdf. Accessed 20 Jul 2019

30. Granta Design Ltd. (2015) CES Selector, www.grantadesign.com, Cambridge. Accessed 24 Jul 2019

31. Thacher EF (2015) A solar car primer: a guide to the design and construction of solar-powered racing vehicles. Springer International Publishing, Switzerland

32. Tamura S (2016) Teijin's advanced carbon fiber technology used to build a car for the World Solar Challenge. Reinf Plast 60(3):160 163. https://doi.org/10.1016/j.repl.2015.12.078

33. Betancur E, Mejía-Gutiérrez R, Osorio-Gómez G, Arbelaez A (2017) Design of structural parts for a racing solar car. In: Eynard
B, Nigrelli V, Oliveri S, Peris-Fajarnes G, Rizzuti S (eds) Advances on mechanics, design engineering and manufacturing lecture notes in mechanical engineering. Springer, Cham, pp 25-32. https://doi. org/10.1007/978-3-319-45781-9_3

34. Lovatt HC, Ramsden VS, Mecrow BC (1998) Design of an inwheel motor for a solar-powered electric vehicle. IEE Proc Electr Power Appl 145(5):402-408. https://doi.org/10.1049/ip-epa: 19982167

35. Tomasini M (2014) Use of fiber-reinforced plastics in wheels for passenger cars. In: Pfeffer P (eds) 5th International Munich Chassis Symposium 2014 Proceedings Springer Vieweg, Wiesbaden 717 739. https://doi.org/10.1007/978-3-658-05978-1_51

36. Schweizer N, Büter A (2013) Development of a composite wheel with integrated hub motor and requirements on safety components in composite. In: Advanced composite materials for automotive applications: structural integrity and crashworthiness, Wiley Online Library, pp 345-370

37. Rossi C, Bertoldi M, Fabbri G, Pontara D, Rizzoli G (2017) Experimental temperature modelization for solar racing vehicle. In: Campana G, Howlett R, Setchi R, Cimatti B (eds) Sustainable design and manufacturing 2017. SDM 2017, Smart innovation, systems and technologies, vol 68. Springer, Cham, pp 829-846

38. Giurgiutiu V (2015) Structural health monitoring of aerospace composites. Academic Press, London

39. Yuan FG (2016) Structural health monitoring (SHM) in aerospace structures. Woodhead Publishing, Duxford

40. Xu Y, Zhu J, Wu Z, Cao Y, Zhao Y, Zhang W (2018) A review on the design of laminated composite structures: constant and variable stiffness design and topology optimization. Adv Compos Hybrid Mater 1(3):460-477. https://doi.org/10.1007/s42114-018-0032-7

41. Ghiasi H, Fayazbakhsh K, Pasini D, Lessard L (2010) Optimum stacking sequence design of composite materials part II: variable stiffness design. Compos Struct 93(1):1-13. https://doi.org/10. 1016/j.compstruct.2010.06.001

42. Klein L (2019) Sensor systems for FRP lightweight structures: automotive features based on serial sensor products. Sensors 19(14): 3088. https://doi.org/10.3390/s19143088

43. Kang SH, Kang M, Kang LH (2018) Piezoelectric smart composite blades for collision monitoring: measurement of mechanical properties and impact sensitivity. Compos Struct 202:1295-1307. https://doi.org/10.1016/j.compstruct.2018.06.065

44. Fleischer J, Teti R, Lanza G, Mativenga P, Möhring HC, Caggiano A (2018) Composite materials parts manufacturing. CIRP Ann 67(2):603-626. https://doi.org/10.1016/j.cirp.2018.05.005

45. Camanho PP, Lambert M (2006) A design methodology for mechanically fastened joints in laminated composite materials. Compos Sci Technol 66(15):3004-3020. https://doi.org/10.1016/j. compscitech.2006.02.017

46. Tong L, Soutis C (2003) Recent advances in structural joints and repairs for composite materials. Springer Science \& Business Media, Dordrecht

47. Egan B, McCarthy CT, McCarthy MA, Frizzell RM (2012) Stress analysis of single-bolt, single-lap, countersunk composite joints with variable bolt-hole clearance. Compos Struct 94(3):10381051. https://doi.org/10.1016/j.compstruct.2011.10.004

48. Madenci E, Barut A, Guven I (2011) Stress analysis of bolted composite joints under multiaxial loading. In: Composite joints and connections - principles, modelling and testing. Woodhead Publishing, Cambridge, pp 186-207

49. Wilhelmsson D, Gutkin R, Edgren F, Asp LE (2018) An experimental study of fibre waviness and its effects on compressive properties of unidirectional NCF composites. Compos A: Appl Sci Manuf 107:665-674. https://doi.org/10.1016/j.compositesa.2018. 02.013 
50. Dransfield K, Baillie C, Mai YW (1994) Improving the delamination resistance of CFRP by stitching-a review. Compos Sci Technol 50(3):305-317. https://doi.org/10.1016/0266-3538(94)90019-1

51. Banea MD, Rosioara M, Carbas RJC, da Silva LFM (2018) Multimaterial adhesive joints for automotive industry. Compos Part B 151:71-77. https://doi.org/10.1016/j.compositesb.2018.06.009

52. Amafabia DAM, Montalvão D, David-West O, Haritos G (2017) A review of structural health monitoring techniques as applied to composite structures. SDHM Struct Durab Health Monit 11(2):91-147. https://doi.org/10.3970/sdhm.2017.011.091.

53. Ono K (2018) Review on structural health evaluation with acoustic emission. Appl Sci 8(6):958. https://doi.org/10.3390/app8060958

54. Minak G, Zucchelli A (2008) Damage evaluation and residual strength prediction of CFRP laminates by means of Acoustic Emission techniques. In: Durand LP (ed) Composites Materials Research Progress, pp 165-209

55. Hofmann P, Walch A, Dinkelmann A, Selvarayan SK, Gresser GT (2019) Woven piezoelectric sensors as part of the textile reinforcement of fiber reinforced plastics. Compos A: Appl Sci Manuf 116: 79-86. https://doi.org/10.1016/j.compositesa.2018.10.019

56. Fabiani D, Grolli F, Selleri G et al (2019) Nanofibrous piezoelectric structures for composite materials to be used in electrical and electronic components. In: Proceedings of the Nordic Insulation Symposium No. 26. pp 1-5

57. Ghafari E, Lu N (2019) Self-polarized electrospun polyvinylidene fluoride (PVDF) nanofiber for sensing applications. Compos Part B 160:1-9. https://doi.org/10.1016/j.compositesb.2018.10.011

58. Boychuk AS, Generalov AS, Stepanov A V (2014) CFRP structural health monitoring by ultrasonic phased array technique. In: EWSHM - 7th European Workshop on Structural Health Monitoring, IFFSTTAR, Inria, Université de Nantes, Jul 2014, Nantes, France. pp 2206-2211

59. VDI (1997) VDI 2225-4:1997 - Design Engineering Methodics Engineering Design at Optimum Cost - Dimensioning

60. Stearns J, Srivatsan T, Gao X, Lam PC (2006) Understanding the influence of pressure and radial loads on stress and displacement response of a rotating body: the automobile wheel. Int J Rotating Mach 2006:1-8. https://doi.org/10.1155/IJRM/2006/60193

61. Grappe F, Candau R, Barbier B, Hoffman MD, Belli A, Rouillon JD (1999) Influence of tyre pressure and vertical load on coefficient of rolling resistance and simulated cycling performance. Ergonomics 42(10):1361-1371. https://doi.org/10.1080/ 001401399185009

62. Solvay Technical Datasheet MTM $® 49-3$ prepreg [https://www. solvay.com/en/product/mtm-49-3]

63. Boisse P, Colmars J, Hamila N, Naouar N, Steer Q (2018) Bending and wrinkling of composite fiber preforms and prepregs. A review and new developments in the draping simulations. Compos Part B 141:234-249. https://doi.org/10.1016/j.compositesb.2017.12.061

64. Povolo M, Raimondi L, Brugo TM, Pagani A, Comand D, Pirazzini L, Zucchelli A (2018) Design and manufacture of hybrid aluminum/composite co-cured tubes with viscoelastic interface layer. Procedia Struct Integr 12:196-203. https://doi.org/10.1016/j. prostr.2018.11.095

65. Nikbakt S, Kamarian S, Shakeri M (2018) A review on optimization of composite structures part I: laminated composites. Compos Struct 195:158-185. https://doi.org/10.1016/j.compstruct.2018.03. 063

66. Lei F, Qiu R, Bai Y, Yuan C (2018) An integrated optimization for laminate design and manufacturing of a CFRP wheel hub based on structural performance. Struct Multidiscip Optim 57(6):2309-2321. https://doi.org/10.1007/s00158-017-1861-7

67. Hammersley JM (1960) Monte Carlo methods for solving multivariable problems. Ann N Y Acad Sci 86(3):844-874. https://doi. org/10.1111/j.1749-6632.1960.tb42846.x

68. Casado JA, Gutiérrez-Solana F, Carrascal I, Diego S, Polanco JA, Hernández D (2016) Fatigue behavior enhancement of short fiber glass reinforced polyamide by adding phase change materials. Compos Part B 93:115-122. https://doi.org/10.1016/j. compositesb.2016.02.059

69. Penrod JP, Dong Y, Buchanan HC (2001) A novel use of a composite material to limit the loads in windshield wiper systems. SAE Technical Paper (No. 2001-01-0104). https://doi.org/10.4271/ 2001-01-0104

70. Bruno L (2018) Mechanical characterization of composite materials by optical techniques: a review. Opt Lasers Eng 104:192-203. https://doi.org/10.1016/j.optlaseng.2017.06.016

71. Palanca M, Brugo TM, Cristofolini L (2015) Use of digital image correlation to investigate the biomechanics of the vertebra. J Mech Med Biol 15(02):1540004. https://doi.org/10.1142/ S0219519415400047

72. Gong W, Chen J, Patterson EA (2015) An experimental study of the behaviour of delaminations in composite panels subjected to bending. Compos Struct 123:9-18. https://doi.org/10.1016/j.compstruct. 2014.12.008

73. Barbero EJ (2013) Finite element analysis of composite materials using Ansys ${ }^{\circledR}, 2$ nd edn. CRC Press, Taylor \& Francis Group, Boca Raton

Publisher's note Springer Nature remains neutral with regard to jurisdictional claims in published maps and institutional affiliations. 